Rafaela Sanches de Oliveira

\title{
Impacto da poluição sonora urbana no \\ desempenho de indivíduos idosos da
}

\section{comunidade: estudo experimental}

Dissertação apresentada a Faculdade de Medicina da Universidade de São Paulo para obtenção do título de Mestre em Ciências.

Programa de Ciências Médica Área de Concentração: Educação e Saúde

Orientador: Wilson Jacob Filho

São Paulo 
Dados Internacionais de Catalogação na Publicação (CIP)

Preparada pela Biblioteca da

Faculdade de Medicina da Universidade de São Paulo

Creprodução autorizada pelo autor

\section{Oliveira, Rafaela Sanches de}

Impacto da poluição sonora urbana no desempenho de individuos idosos da comunidade : estudo experimental / Rafaela Sanches de Oliveira. - São Paulo, 2014.

Dissertação(mestrado)--Faculdade de Medicina da Universidade de São Paulo.

Programa de Ciências Médicas. Área de concentração: Educação e Saúde. Orientador: Wilson Jacob Filho.

Descritores: 1.Idoso 2.Envelhecimento 3.Poluição sonora 4.Cognição 5.Equilibrio postural 6.Força muscular

USP/FM/DBD-120/14 
Dedico esta dissertação aos meus pais Neide e João Gualberto, que seguraram minha mão no lápis desde os primeiros traços, me apoiando em cada decisão, sempre me encorajando, com amor e transmitindo ensinamentos que formaram os alicerces de minha história. Ao meu companheiro Renato, que sempre me acompanhou e soube me compreender ao longo desta trajetória, me incentivando a concretizar este sonho. 


\section{Agradecimentos}

Inicio meus agradecimentos por Deus, já que Ele colocou pessoas tão especiais ao meu lado, sem as quais certamente não teria conseguido.

Agradeço ao Prof. Wilson Jacob Filho, por acreditar que eu seria capaz e pela orientação. Mesmo chegando sem me conhecer direito, você me

recebeu com seu jeito acolhedor. Só tenho a agradecer aos seus ensinamentos (pessoais e acadêmicos), orientações, palavras de incentivo, puxões de orelha, paciência e dedicação. Você é uma pessoa ímpar, onde busco inspirações para ser melhor. Tenho orgulho em dizer que sou sua orientada.

Ao Prof. Alexandre Leopold Busse por participar em todos os momentos do meu processo de amadurecimento e desenvolvimento deste projeto. Pela atenção e dedicação com que sempre me tratou.

À Beatriz Maria Trezza por me permitir fazer parte do seu sonho, me recebendo de braços abertos e ajudando em todas as etapas deste.

Aos funcionários do NAPPEG, em especial à Angela, que sempre se colocou a disposição para me ajudar, sempre com um sorriso no rosto.

Aos funcionários da pós-graduação Clinica Médica, especialmente a Angélica e a Rose pela disponibilidade, simpatia e gentileza.

Aos voluntários deste estudo, pela disponibilidade em participar e pelo carinho com que me trataram durante todos os nossos encontros. 


\section{Normalização}

Esta dissertação está de acordo com as seguintes normas, em vigor no momento desta publicação:

Referências: adaptado de International Committee of Medical Journals Editors (Vancouver).

Universidade de São Paulo. Faculdade de Medicina. Divisão de Biblioteca e Documentação. Guia de apresentação de dissertações, teses e monografias. Elaborado por Anneliese Carneiro da Cunha, Maria Julia de A. L. Freddi, Maria F. Crestana, Marinalva de Souza Aragão, Suely Campos Cardoso, Valéria Vilhena. 3a ed. São Paulo: Divisão de Biblioteca e Documentação; 2011.

Abreviaturas dos títulos dos periódicos de acordo com List of Journals Indexed in Index Medicus. 
Lista de figuras

Lista de tabelas

Lista de quadros

Lista de abreviaturas

Lista de símbolos

Resumo

Abstract

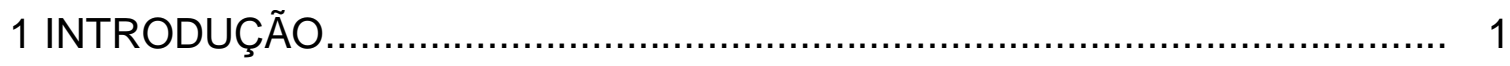

1.1 Envelhecimento populacional.............................................. 2

1.2 Funcionalidade no idoso........................................................ 3

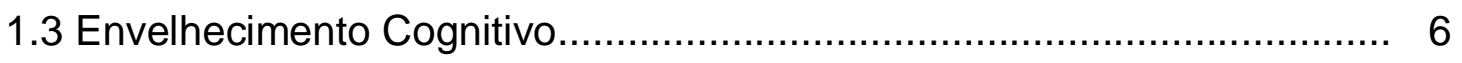

1.4 Envelhecimento: Força e Equilíbrio Corporal................................. 9

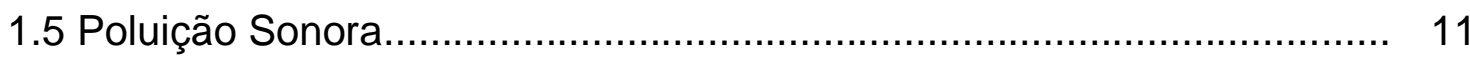

1.6 Ruídos e suas repercussões................................................... 12

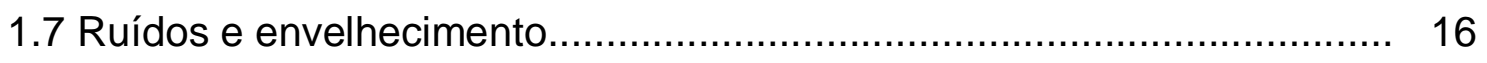

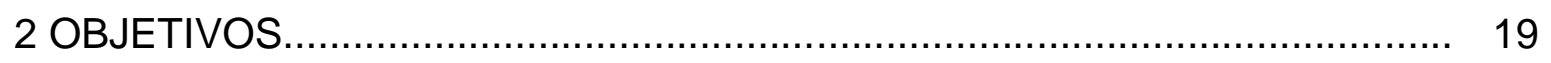

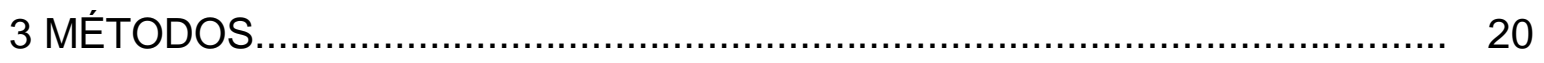

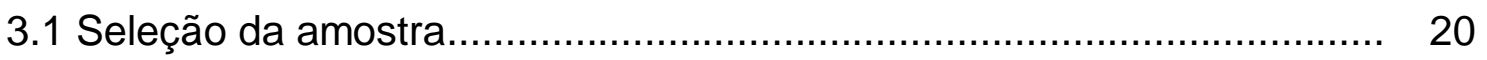

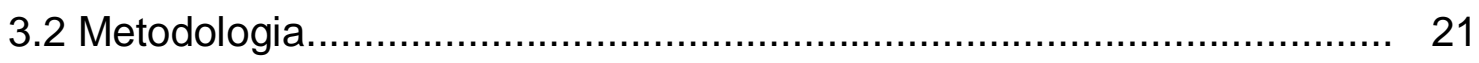

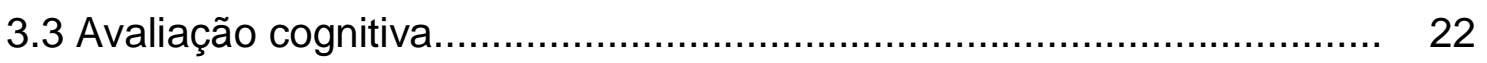

3.4 Avaliação do equilíbrio........................................................ 28 
3.4.2 LoS Limity of Stability ......................................................... $\quad 30$

3.5 Avaliação da força muscular voluntária................................................. 33

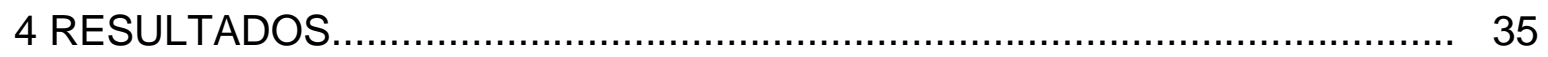

4.1 Análise descritiva de caracterização da amostra estudada..................... 36

4.2 Avaliação do desconforto............................................................... 37

4.3 Comparação entre os resultados dos testes realizados em ambiente controlado e os testes realizados com ruído.

4.4 Comparação da diferença entre as situações ambiente controlado e com presença de ruído.

5 DISCUSSÃO. 45

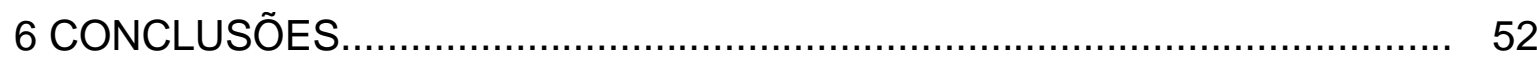

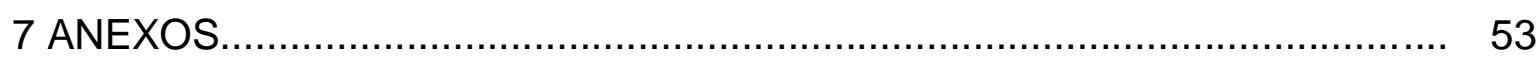

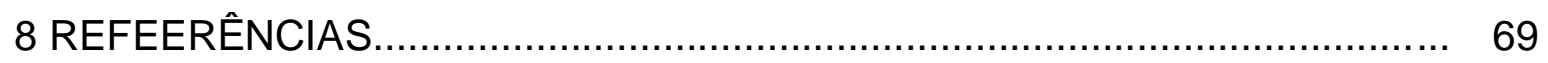

Apêndice 


\section{LISTA DE FIGURAS}

Figura 1 - Tela inicial do teste Trail Making A do site Lumosity.......................... 23

Figura 2 - Tela do teste Trail Making B, em andamento, do site Lumosity........... 24

Figura 3 - Tela inicial e final do teste Spatial Recognition, do site Lumosity........... 25

Figura 4 - Tela inicial do teste Go/No-Go do site Lumosity.............................. 25

Figura 5 - Tela da teste Go/No-Go em andamento, do site Lumosity................... 26

Figura 6 - Tela inicial e final do teste Pattern Recognition do site Lumosity........... 26

Figura 7 - Tela inicial do teste Memory Spam e Reverse Memory Spam do site Lumosity..........................................................................................

Figura 8 - Plataforma de força (Basic Balance System - NeuroCom)................ 29

Figura 9 - Tela do teste clínico modificado de interação sensorial sobre o equilíbrio (modified Clinical Test of Sensory Interaction on Balance $m C T S I B)$ da plataforma de força (Basic Balance System NeuroCom).

Figura 10 - Tela do teste de Limites de Estabilidade (LoS - Limits of Stability test) na plataforma de força (Basic Balance System - NeuroCom)..............

Figura 11 - Relatório produzido pelo Balance Master indicando valores normais no Teste de Limites de Estabilidade para um idoso com 79 anos....... 


\section{LISTA DE TABELAS}

Tabela 1 - Características sociodemográficas da amostra estudada.

Tabela 2 - Comparação dos resultados dos testes T1 e T2 da função cognitiva....

Tabela 3 - Comparação dos resultados dos testes de função cognitiva em ambiente controlado e com ruído.

Tabela 4 - Comparação dos resultados do teste de equilíbrio, na plataforma de pressão, CTSIB em ambiente controlado e com ruído, nas diferentes situações sensoriais.

Tabela 5 - Comparação dos resultados da variável Tempo de Reação (TR), realizada para a avaliação do equilíbrio na plataforma de pressão nos testes de em ambiente controlado e com ruído, nas diferentes direções.

Tabela 6 - Comparação dos resultados da variável Velocidade do Movimento (VM), realizada para a avaliação do equilíbrio na plataforma de pressão nos testes de em ambiente controlado e com ruído, nas diferentes direções.

Tabela 7 - Comparação d os resultados da variável Ponto Final de Excursão (PFE), realizada para a avaliação do equilíbrio na plataforma de pressão nos testes de em ambiente controlado e com ruído, nas diferentes direções.

Tabela 8 - Comparação dos resultados da variável Excursão Máxima (EM), realizada para a avaliação do equilíbrio na plataforma de pressão nos testes de em ambiente controlado e com ruído, nas diferentes direções.

Tabela 9 - Comparação dos resultados da variável Controle de Direção (CD), realizada para a avaliação do equilíbrio na plataforma de pressão nos testes de em ambiente controlado e com ruído, nas diferentes direções.

Tabela 10 - Comparação dos resultados do teste de preensão manual realizado em ambiente controlado e com ruído.

Tabela 11 - Impressão de desconforto relatada pelos idosos na realização dos testes com ruído. 


\section{LISTA DE QUADROS}

Quadro 1 - Protocolo Experimental.............................................................. 22 


\section{LISTA DE SIGLAS}

AVD Atividade de Vida Diária

AIVD Atividade Instrumental de Vida Diária

CDM Centro de Massa

CG Centro de Gravidade

CNPq Conselho Nacional de Desenvolvimento Cientifico e Tecnológico

GABA Ácido Gama-aminibutírico

GDS Geriatric Depression Scale

HCFMUSP Hospital das Clínicas da Faculdade de Medicina da Universidade de São Paulo

IBGE Instituto Brasileiro de Geografia e Estatística

OMS Organização Mundial de Saúde

PNAD Pesquisa Nacional por Amostra de Domicílios

ITTS Temporary Threshould Shift

LoS Limitis of Stability Test

mCTSIB modified Clinical Test of Sensory Interaction on Balance

MEEM Mini Exame do Estado Mental

PAIR Perda Auditiva Induzida por Ruído

SGA Síndrome Geral da Adaptação

SNA Sistema Nervoso Autônomo

SNC Sistema Nervoso Central

SPPB Short Physical Performance Battery

SPSS 18.0 Statistical Package for Social Science, version 18.0

WHO World Health Organization 


\section{LISTA DE SÍMBOLOS}

$\begin{array}{cl}\mathrm{cm} & \text { centímetro } \\ \mathrm{dB}(\mathrm{A}) & \text { decibéis } \\ \mathrm{Hz} & \text { hertz } \\ \mathrm{kg} / \mathrm{m}^{3} & \text { quilograma por metro cúbico } \\ \mathrm{L}_{\mathrm{eq}} & \text { nível sonoro equivalente } \\ \mathrm{ms} & \text { milissegundo } \\ \mathrm{m} / \mathrm{s} & \text { metro por segundo } \\ \mathrm{s} & \text { segundo } \\ \text { o } / \mathrm{s} & \text { graus por segundo }\end{array}$




\section{RESUMO}

Oliveira RS. Impacto da poluição sonora urbana no desempenho de indivíduos idosos da comunidade: estudo experimental [dissertação]. São Paulo: Faculdade de Medicina. Universidade de São Paulo; 2014.

INTRODUÇÂO: O envelhecimento da população e a poluição são duas preocupações crescentes para as próximas décadas. Os idosos são mais suscetíveis a estressores e dessa forma podem ter mais facilmente comprometida sua capacidade funcional e independência. Com o crescimento dos centros urbanos aumentam as diferentes formas de poluição, sendo a sonora uma das mais relevantes. Visto que a poluição sonora pode ser encarada como um fator estressante, nosso objetivo foi avaliar o impacto dos ruídos sonoros no desempenho funcional de idosos da comunidade. MÉTODOS: Estudo transversal com 20 idosos selecionados no ambulatório de geriatria com idade entre 60 e 80 anos. A avaliação cognitiva foi computadorizada e realizada por 4 vezes, sendo as duas primeiras em ambiente com ruído controlado, visando atenuar o aprendizado e as duas finais, incluindo as avaliações de equilíbrio em plataforma de pressão e força muscular, com teste de preensão palmar , uma vez em ambiente controlado e a outra vez com o ruído sonoro. Estes foram provenientes de uma gravação em um centro urbano, com intensidade oscilando entre 75 e $80 \mathrm{~dB}$ (A), frequência sonora aleatória e flutuante afim de não causar acomodação. RESULTADOS: A média de idade da amostra foi de 72,20 anos, sendo 10 mulheres. Entre as duas avaliações cognitivas iniciais observamos efeito de aprendizado apenas no teste Trial Making $A$ com valor de $\mathrm{p}=0,019$, sendo este o primeiro teste da série realizada. Nas demais avaliações cognitivas, visando comparar o desempenho mediante a presença de ruído, observamos a melhora do desempenho somente nos testes Trail Making $A$ e $B$, com valor de $p=0,028$ e 0,008 respectivamente. Nos testes de equilíbrio a variável velocidade do movimento elevou-se na presença do ruído $(p=0,028)$ bem como a excursão máxima $(p=0,011)$, ambas a direita, sendo todos destros. No teste de força muscular não observamos alteração do desempenho. CONCLUSÔES: Os ruídos sonoros alteram a função cognitiva dos idosos da comunidade, melhorando o desempenho em testes de atenção, o que não foi possível observar nos testes de equilíbrio e de funções motoras.

Descritores: Idoso; Envelhecimento; Poluição Sonora; Cognição; Equilíbrio Postural; Força Muscular. 


\begin{abstract}
Oliveira RS. Impact of urban noise pollution on functional performance in elderly individuals in community: an experimental study [dissertation]. São Paulo: Faculdade de Medicina. Universidade de São Paulo; 2014.

INTRODUCTION: The aging population and pollution are two growing concerns for the coming decades. The elderly are more susceptible to stressors and thus may be more easily compromised functional capacity and independence. With the growth of urban centers increase the different forms of pollution, noise being one of the most relevant. Since noise pollution can be seen as a stressor, our goal was to evaluate the impact of sound noise in functional performance of older adults. METHODS: Cross-sectional study with 20 participants selected from the outpatient geriatric aged between 60 and 80 years. The cognitive assessment was computed and held for 4 times, the first two being in an environment with controlled noise to mitigate learning and the final two , including assessments of balance in pressure and muscle strength platform with handgrip test, a once in the controlled environment and again with the sound noise. These were from a recording in an urban center, with intensity ranging between 75 and $80 \mathrm{~dB}(\mathrm{~A})$, and fluctuating frequency random noise in order not to cause accommodation. RESULTS: The mean age was 72.20 years, and 10 women. Between the two initial cognitive assessments observed learning effect only on Trial Making Test $A$ $p$-value $=0.019$, which is the first test series performed. In other cognitive appraisals, in order to compare the performance through the presence of noise, we observe the performance improvement only in the Trail Making Tests $A$ and $B$, with $p=0.028$ and 0.008 respectively. On the balance tests the variable speed of movement increased in the presence of noise $(p=0.028)$ and the maximum excursion ( $p=0.011$ ), both right, being right-handed. In muscle strength testing we observed no change in performance. CONCLUSIONS: The audible noise alter the cognitive function of older adults, improving performance on tests of attention, which was not observed in balance and motor function tests.
\end{abstract}

Descriptors: Aged, Aging, Noise pollution, Cognition, Postural balance, Muscle strength. 


\section{INTRODUÇÃO}

A poluição sonora é um problema crescente da sociedade moderna. Sua causa está intimamente ligada ao desenvolvimento dos centros urbanos. $O$ crescente aumento do trânsito nas ruas e estradas, a expansão das zonas residenciais, aproximando-se de aeroportos e a alta demanda da construção civil são alguns dos fatores causadores dos ruídos nos centros urbanos. Estima-se que nas próximas décadas a emissão de ruídos intensos aumente proporcionalmente ao crescimento urbano.

A Organização Mundial de Saúde (OMS) afirma que a poluição sonora é um dos problemas do ambiente que mais atinge os sentidos humanos, em geral de menor importância apenas que a poluição atmosférica e da água. Porém, dados recentes apontam que na Europa, a poluição sonora já ocupa o segundo lugar, ultrapassando a magnitude da poluição da água. Existe uma significativa associação entre ruído urbano e efeitos deletérios ao organismo. A exposição contínua a ruídos intensos pode ocasionar danos auditivos e extra-auditivos, físicos, mentais e sociais (WHO, 2011).

Os idosos correspondem a um segmento da população que pode ser mais suscetível aos insultos ambientais, devido a uma diminuição na habilidade de compensar a ação desses estressores. $O$ processo fisiológico do envelhecimento frequentemente leva a uma presbiacusia, com perda neurosensorial simétrica, bilateral e lentamente progressiva de sons com freqüência acima de $2000 \mathrm{~Hz}$ (Souza e Russo, 2009). Porém esta alteração não interfere no desconforto ocasionado pela poluição sonora, visto a grande variação de frequencias envolvidas.

O aumento da longevidade e a redução das taxas de mortalidade, nas últimas décadas do século passado, mudaram o perfil demográfico do Brasil. Rapidamente, deixamos de ser um "país de jovens" e o envelhecimento tornouse questão fundamental para as políticas públicas. Os brasileiros com mais de 60 anos já representam $12,6 \%$ da população, conforme a Pesquisa Nacional por Amostra de Domicílios - PNAD de 2012, sendo que na Região Sudeste, as 
mulheres correspondiam a $15,1 \%$ da população e os homens $12,4 \%$ (IBGE, 2012a).

\subsection{Envelhecimento Populacional}

Cada vez mais presente na realidade da sociedade brasileira, o tema envelhecimento populacional vem sendo trabalhado em pesquisas nas últimas décadas. O interesse crescente no estudo deste assunto se dá pelo rápido crescimento dessa população (Kalache, 2008).

A definição do que é um idoso depende de variados aspectos, desde culturais até biológicos, o que dificulta uma precisão. Contudo, devido a necessidades práticas, como a adoção de políticas públicas, a OMS recomenda adotar para os países em desenvolvimento, como o Brasil, o limite etário de 60 anos ou mais, e 65 anos ou mais para os países desenvolvidos (Camarano e Pasinato, 2004).

O envelhecimento da população ocorre no Brasil de forma mais rápida e intensa do que ocorreu nos países desenvolvidos. Isso se deve ao fato que nos países desenvolvidos não observamos o crescimento da taxa de fertilidade observada no Brasil nas décadas passadas. Os países desenvolvidos já apresentavam um número inferior de jovens mesmo antes de ocorrer a diminuição da taxa de mortalidade (Brito, 2007).

O número de idosos no Brasil passou de 3 milhões, em 1960, para 7 milhões, em 1975, e 20 milhões em 2010, promovendo um aumento de quase $700 \%$ em cerca de 50 anos (Veras, 2009). As estimativas apontam que essa população idosa irá mais do que triplicar nas próximas quatro décadas, de 20 milhões em 2010 para aproximadamente 65 milhões em 2050 (World Bank, 2011). Segundo dados do Instituto Brasileiro de Geografia e Estatística - IBGE o percentual de indivíduos com 65 anos ou mais na população que correspondia a 4,8\% na década de 90, em 2000 passou para 5,9\% e em 2010 já representa 7,4\% da população total (IBGE, 2011).

O ritmo de crescimento da população brasileira tem sido bastante sistemático e expressivo. A taxa de fecundidade total (número médio de filhos que uma mulher teria até o final do seu período fértil) era de 2,3 em 2005, em 
2006 diminuiu para 2,0, em 2009 foi para 1,94 e continuou caindo alcançando 1,86 em 2010 (IBGE, 2011). Esse valor não expressa o necessário para a reposição natural da população. Somado ao fato de uma menor quantidade de nascimentos temos um aumento na expectativa de vida ao nascer. Em 2011 a expectativa de vida ao nascer era de 74,1 anos, aumentando para 74,6 anos em 2012 , sendo que para os homens passou de 70,6 para 71 anos e de 77,7 para 78,3 anos para as mulheres (IBGE, 2012b).

A diferença entre homens e mulheres deverá aumentar ainda mais nos próximos anos. As estimativas para 2050 apontam que $51,60 \%$ da população será composta por mulheres, enquanto que em 2012 correspondiam a 51,33\%. $\mathrm{Na}$ contagem geral de nascimentos os homens possuem maior representatividade, porém ao observar as faixas etárias mais elevadas, as mulheres se destacam. Deste modo nas faixas mais elevadas, como em 80 anos ou mais, as mulheres correspondem a $61,40 \%$ da população e passarão em 2050 para 62, 91\% (IBGE, 2012a; United Nation, 2009).

\subsection{Funcionalidade do idoso}

O aumento da população idosa sucinta preocupação com as condições de saúde. Envelhecer e manter íntegro o funcionamento orgânico e psicossocial não implica em problema, quer para o indivíduo, quer para a família e a comunidade.

Segundo Araújo e Caldas (2002) o envelhecimento pode ser divido em senescência, quando ocorre a perda gradual das funções orgânicas, mantendo sua capacidade intelectual e física em níveis aceitáveis; e em senilidade, quando aparecem degenerações intensas caracterizando o envelhecimento patológico.

Atualmente acreditamos que a senescência compreenda as alterações que são inerentes ao processo do envelhecimento, que ocorrem a todos os indivíduos e não acarretam prejuízo funcional, já a senilidade, envolveria as situações patológicas que se responsabilizam pelos comprometimentos da autonomia e da independência (Jacob-Filho et al., 2005).

Quando as alterações estruturais e funcionais, promovidas pelo envelhecimento, desafiam a reserva funcional do idoso a atingir seu limiar, os 
problemas e as queixas quanto à saúde começam a surgir. Este conceito vem de encontro ao proposto por Comfort (1979), no qual afirma que o envelhecimento seria a perda progressiva da capacidade de manutenção da homeostase, em condições de sobrecarga funcional. A capacidade de manutenção da homeostase pode ser interpretada como uma reserva funcional que sofre um declínio progressivo com o processo do envelhecimento. Esse prejuízo na reserva funcional torna o idoso mais vulnerável a doenças e a sobrecargas. Assim a senescência permite que o idoso sobreviva sem prejuízo funcional em condições normais, porém em situações de estresses emocionais e físicos podem apresentar descompensações.

O desequilíbrio entre um ou mais fatores como, saúde física, mental, integração social, independência nas atividades diárias, independência econômica e suporte familiar, pode comprometer a capacidade funcional dos idosos (Duarte e Diogo, 2000; Ramos, 2003).

O termo incapacidade funcional refere-se à dificuldade ou impossibilidade do indivíduo em executar suas atividades de vida diária e embora os fatores desencadeantes estejam diretamente ligados a doenças, fatores demográficos, psicossociais, socioeconômicos, culturais, autocontrole e relacionamentos interpessoais também atuam de forma secundária na sua instalação (Rosa et al 2003).

A independência do idoso é frequentemente medida como a capacidade funcional de realizar as atividades de vida diária (AVD). Elas consistem em tarefas como banhar-se, vestir-se, alimentar-se, ir ao toalete, realizar transferências e manter as continências. Embora esta avaliação seja bastante útil, a realização apenas destas tarefas não garante a habilidade necessária para uma vida independente. Para completar esta avaliação é apropriado questionar sobre a realização de atividades instrumentais de vida diária (AIVD), tais como: cozinhar, fazer compras, fazer tarefas domésticas, usar o telefone, usar meios de transporte, gerenciar finanças e medicações (Katz et al, 1963; Lawton, Brody, 1969; Gompertz et al., 1994).

Diante dos potenciais fatores de risco, a manutenção da qualidade de vida torna-se mais desafiadora. Uma avaliação geriátrica eficiente e completa, a custos razoáveis, torna-se cada vez mais premente. Seus objetivos são o 
diagnóstico precoce de problemas de saúde e a orientação de serviços de apoio onde e quando forem necessários, com a finalidade de manter as pessoas nos seus lares. A história, o exame físico e o diagnóstico diferencial tradicional não são suficientes para um levantamento extenso das diversas funções necessárias à vida diária do indivíduo idoso. A prática clínica geriátrica deve se preocupar com a qualidade de vida e deve conter também uma ampla avaliação funcional em busca de perdas possíveis destas funções (Paixão JR e Heckamnn, 2005).

Entre as formas de avaliar a funcionalidade do idoso encontramos a observação direta, através de testes de desempenho e a aplicação de questionários, quer auto-aplicativos ou através de entrevistas, colhendo os dados diretamente com o paciente. Estas avaliações são sistematizadas por meio de escalas que aferem os componentes das dimensões físicas, sensoriais, cognitivas entre outras (Paixão JR e Heckamnn, 2005).

As alterações e os déficits causados pelo declínio cognitivo levam ao declínio funcional, com diminuição e/ou perdas das habilidades para 0 desenvolvimento das atividades cotidianas, interferindo de forma significativa na realização das atividades de vida diária. Com o agravo do quadro pode ocorrer dificuldade no seu autocuidado, comprometimento da linguagem, incapacidade de orientar-se e reconhecer fisionomias, alterações no sono e déficits de locomoção (Argimon e Stein, 2005; Ruwer e Rossi, 2005).

Os instrumentos adequados para realizar a avaliação neuropsicológica devem ser sensíveis para detectar déficits sutis no desempenho e dessa forma facilitar a intervenção precoce. A avaliação neuropsicológica é composta por testes que mensuram: atenção, memória, funções executivas, linguagem, apraxias, gnosias e demais habilidades associadas ao desempenho cognitivo, como concentração, raciocínio, aprendizagem e inteligência (Memória, 2011).

Segundo Green et al. (1994) as baterias de testes computadorizados podem contribuir para detectar os mínimos desvios da normalidade. Trazem como vantagens maior consistência e padronização, redução de eventuais falhas na aplicação, inexistência da latência do examinador ao anotar as respostas do avaliado, minimização dos erros na correção, acessibilidade financeira, além de gerar relatórios automáticos dos resultados. 
Outro mecanismo que também contribui para o comprometimento do desempenho funcional do idoso é o declínio do equilíbrio postural e da mobilidade, que podem ter seu início facilitado pelo processo do envelhecimento e agravados por condições patológicas. Essas manifestações de desequilíbrios causam grande impacto, levando à redução de sua autonomia social, uma vez que acabam reduzindo suas atividades de vida diária, pela predisposição a quedas e fraturas, trazendo sofrimento, imobilidade corporal, medo de cair e altos custos com o tratamento de saúde (Ferrucci et al., 2004; Ruwer e Rossi, 2005).

Vários testes de equilíbrio são usados para determinar deficiências nos componentes de controles posturais em idosos (Patla e Frank, 1990). Essa avaliação é fundamental para detectar e tratar alterações precoces, mantendo ou devolvendo a funcionalidade do indivíduo. Existem diversas formas de avaliação do equilíbrio e mobilidade, desde testes de desempenho em atividades que desafiam as funções somatossensoriais e vestibulares, de baixo custo e fácil aplicação até testes realizados em equipamentos de alto custo, que produzem variáveis mais sensíveis detectando pequenas oscilações do centro de gravidade, como as plataformas de pressão (Bizzo et al., 1985).

\subsection{Envelhecimento cognitivo}

Para o entendimento do funcionamento cerebral no idoso, é essencial o conhecimento do impacto multifacetado da senescência no cérebro e suas consequências sobre o comportamento. O avanço da idade trás consigo uma variedade de alterações neurais, na substância cinzenta, no córtex cerebral, na substância branca, no fluxo sanguíneo cerebral e nas atividades funcionais. A relação entre as mudanças neuronais ocasionadas pelo envelhecimento e as expressões clínicas e cognitivas ainda não estão inteiramente claras. Em alguns indivíduos encontramos evidência de declínios cognitivos graves, enquanto em outros não observamos expressões clínicas ou cognitivas relevantes (Steffener et al., 2011).

O processo de envelhecimento gera diversas alterações macro e microscópicas no encéfalo, as quais incluem o peso e o volume do órgão; o 
aspecto dos giros e sulcos; o volume dos ventrículos; o tamanho e o número dos neurônios, além da extensão da ramificação dendrítica; o número de espículas e de sinapses; o acúmulo de pigmento de lipofuscina nos neurônios e células gliais, aumento de radicais livres, influxo de cálcio intracelular e o aparecimento de modificações microscópicas características, como as placas senis, os emaranhados neurofibrilares, a degeneração granulovacuolar, os corpos de Hirano e a angiopatia amilóide cerebral (Cançado 2002; Silva 2007).

Durante o envelhecimento ocorre diminuição na produção, liberação e metabolismo dos neurotransmissores. Os dopaminérgicos, mais afetados, são responsáveis por alterações motoras em idades avançadas. Outros neurotransmissores, também afetados são: GABA (ácido gama-aminobutírico), serotonina, catecolaminas, acetilcolina, receptores colinérgicos (Cançado, 2002).

Entre as repercussões clínicas das alterações estruturais, o declínio da memória é um dos mais relevantes. A memória episódica sofre mais prejuízo que a memória semântica e observamos um declínio da memoria operacional e da memória recente mais evidente que as perdas de memória imediata e remota. Em ordem crescente de comprometimento podemos citar os prejuízos na memória de procedimento, reaprendizado, de reconhecimento, de evocação baseada em pistas, evocação livre e memória prospectiva. Encontramos dificuldades em aprender informações novas, evocar tardiamente e repetir números em ordem inversa. Já o vocabulário, o fundo de informações e a repetição numérica na ordem direta, assim como as atividades diárias e automáticas, mantêm-se relativamente preservadas (Craik, 1990; Fournet et al., 2012).

Outra habilidade, bastante alterada pelo envelhecimento, é a função executiva. Esta apresenta declínio devido a alterações no planejamento, inibição e fluência verbal, dificultado a autorregulação do comportamento e o processamento de forma eficaz de grande quantidade de informação (Van Hooren et al., 2007).

O estudo da linguagem no envelhecimento relata que não ocorre prejuízo do processamento sintático e do vocabulário, porém altera a lembrança das palavras, podendo ocasionar parafasias semânticas. Parafasias narrativas 
também podem ser visualizadas devido a dificuldades em sumarização, interpretação moral e inferências. (Ulatowska et al., 1985; Dixon et al., 1993).

A capacidade de se concentrar em informações importantes diminui com o envelhecimento. Isso porque ocorre perda da capacidade de inibir estímulos irrelevantes e valorizar estímulos relevantes, selecionando aquilo que é fundamental para a realização de uma tarefa (Vergaeghen e Cerella, 2002). Juola et al. (2000) afirmam que o envelhecimento leva a uma diminuição da capacidade de inibir respostas inadequadas diante de testes de atenção. A atenção sustentada não sofre prejuízo segundo Berardi et al. (2001), a dificuldade estará em realizar tarefas simultâneas, e portanto em dividir a atenção. A capacidade de alternar rapidamente entre tarefas, designada comutação, também sofre declínio, dificultando a transferência da atenção (Mayr e Kliegl, 2000).

O funcionamento visuo-espacial sofre perturbação independente das perdas visuais. Ronnlund e Nilsson (2006) afirmam que ocorrem mudanças no processamento e construção visuo-espacial, na rotação mental e dificuldade para copiar figuras complexas.

Embora os estudos apontem para estas alterações funcionais, as perdas não ocorrem de forma homogênea na população idosa. Estudo realizado por Ardilla (2007) mostrou que, diferentemente do que é observado nas faixas etárias mais jovens, os idosos demonstram uma grande variância nos resultados, principalmente na avaliação das funções executivas.

Semelhante ao conceito de reserva funcional, proposto por Comfort (1979), Stern (2002) e Stern et al., (2008) afirmam que a reserva cognitiva é responsável pela diferença no desempenho do idoso diante do envelhecimento neural. Segundo os autores, esta reserva cognitiva tende a proteger o indivíduo dos efeitos deletérios da senilidade. Ela seria produto da inteligência inata e das experiências e exposições às quais o indivíduo se submeteu no decorrer da vida. Estudos apontam para a melhora da reserva funcional à medida que aumenta a capacidade sináptica neuronal, devido à maior eficiência das redes neuronais e do uso de estratégias alternativas, levando a menor chance de desenvolver demências (Katzman et al., 1989; Vann Praag et al., 1999; Cabeza et al., 2002; Stern, 2002; Kemppainen et al., 2008). 


\subsection{Envelhecimento: Força e Equilíbrio Corporal}

O equilíbrio corporal é definido como a manutenção de uma postura particular do corpo com um mínimo de oscilação, tratando-se do equilíbrio estático (sistema dos segmentos articulados em repouso) e a manutenção da postura antigravitacional, dependente de uma série de sistemas organizados não apenas hierarquicamente, mas também de maneira paralela e distribuída, definido dessa forma como equilíbrio dinâmico. Para realizar esta atividade motora complexa é necessário a integração de informações sensoriais, planejamento e execução de padrões de movimentos adequados (Horak e Macpherson, 1996; Figueiredo et al. 2007).

Para regular o equilíbrio, o Sistema Nervoso Central (SNC) precisa ser continuamente informado sobre a posição do Centro de Gravidade (CG), o que possivelmente é condicionado a uma representação interna do corpo no espaço (Morasso et al., 1999; Shumwaycook e Woollacott, 1995).

Os estímulos que quantificam o estado de configuração espacial do corpo são reconhecidos por receptores especializados, organizados em sistemas sensoriais específicos. O sistema de controle postural utiliza-se do sistema sensorial para obter informações sobre a posição e a trajetória do corpo. Esse sistema sensorial compreende os sistemas visuais, somatossensorial e vestibular. As informações recebidas pelo SNC necessitam ser harmoniosas e precisas; qualquer perturbação nesse conjunto de informações pode acarretar alterações no estado de equilíbrio corporal, ocasionando, por exemplo, a tontura (Morasso e Schieppati, 1999; Ganança et al., 2000; Stoffregen et al., 2000, Shubert e Minor, 2004; Ruwer e Rossi, 2005).

Os órgãos do equilíbrio, localizados em ambos os lados da cabeça, no ouvido interno, contribuem constantemente para evitar a instabilidade casual do corpo humano, tanto durante o estado de repouso como em locomoção. A orelha interna é constituída por um complexo sistema de sacos e túbulos chamado de labirinto membranoso, que contém uma substancia viscosa, a endolinfa. Parte desta estrutura, que corresponde a uma forma cônica, concerne à audição, enquanto todo o restante é diferenciado para o equilíbrio, constituindo o sistema vestibular (Shubert e Minor, 2004; Ruwer e Rossi, 2005). 
Uma vez que o labirinto é formado pelos órgãos sensoriais da audição e do equilíbrio corporal, há uma estreita relação anatômica entre esses sistemas. $O$ sáculo (parte integrante do sistema vestibular) se une ao ducto coclear (parte do sistema auditivo) pelo ducto reuniens (Munhoz et al., 2003).

O sistema vestibular funciona em comum com os outros dois para manter o controle postural, e este é composto de três partes: o primeiro é um componente sensorial (está localizado no ouvido interno) ligado à segunda parte, que é o processador central (localizado na ponte ou núcleo vestibular e cerebelo) este recebe e integra os sinais, combinando com informações somatossensoriais e visuais enviando para o terceiro componente, o controle motor que se utiliza dos músculos oculares e da medula espinhal (Lord et al., 1994).

Das alterações relacionadas com o aparelho vestibular, destaca-se a presbivertigem, por associar-se ao processo de degeneração das estruturas pertencentes ao sistema vestibular. Com o envelhecimento ocorrem perdas no sistema vestibular, aproximadamente $40 \%$ das células ciliares dos canais semicirculares, depois dos 70 anos. Portanto, a diminuição da sensibilidade cutânea, da propriocepção, da acuidade visual e da sensibilidade de contraste favorece o risco de quedas devido às funções sensoriais estarem alteradas (Paixão JR, Heckamnn, 2002).

O sistema neuromuscular deve ser considerado responsável pelo controle postural, tendo como função a coordenação das forças, que agem para equilíbrio do corpo no espaço. O processo do envelhecimento afeta os componentes do controle postural, sendo difícil diferenciar os efeitos da idade daqueles causados pelas doenças e estilo de vida. Contudo a alteração do equilíbrio diminui a capacidade compensatória do indivíduo, aumentando a sua instabilidade e, consequentemente seu risco de cair (Gonçalves et al.,2009).

Segundo Chandler (2002), as alterações no equilíbrio postural causadas pelo envelhecimento estão ligadas aos distúrbios funcionais dos sistemas de controle e execução, seja como decorrência de doenças e/ou estilo de vida deletério. Alguns componentes encontram-se alterados, sendo importante salientar:

- distúrbios musculoesqueléticos, como a diminuição da força muscular causada pela perda e redução do tamanho das fibras musculares, 
principalmente as fibras do tipo Ilb e restrição das amplitudes articulares, como a limitação da dorsiflexão plantar;

- sensoriais (déficits somatossensoriais, visuais e vestibulares);

- retardo do processamento das informações.

Em adendo Gonçalves et al. (2009) adiciona:

- a menor sensibilidade dos reflexos de estiramento;

- redução ou ausência do reflexo aquileu;

- maior oscilação;

- menor velocidade de marcha;

- redução de reflexos autonômicos, como as alterações promovidas pelo envelhecimento que favorecem a perda do equilíbrio.

- Na ausência de doenças, estas mudanças resultam em sintomas leves com pouca ou nenhuma restrição às atividades de vida diária. Estas alterações, no entanto, tornam-se sintomáticas na presença de doenças, estressores farmacológicos e ambientais.

A força muscular, como mencionada anteriormente, também está comprometida pelo processo do envelhecimento. Isso ocorre devido a redução das fibras musculares, especialmente as do tipo Ilb, levando a uma diminuição da força global, preferencialmente nos membros inferiores, o que favorece a perda de equilíbrio. Mesmo com o prejuízo da performance com 0 envelhecimento, Marchan et al., (2009), afirmaram que a concentração durante a atividade muscular, focada na musculatura que realiza o movimento, aumenta a eficácia nas tarefas realizadas, fator importante para a manutenção da funcionalidade e equilíbrio. Deste modo, a presença de fatores que comprometam a atenção como os ruídos sonoros podem dificultar essas funções.

\subsection{Poluição Sonora}

Poluição envolve qualquer destruição, degradação ou estrago das condições ambientais, do habitat e da coletividade humana. Esta mudança ambiental leva a um prejuízo, mesmo que relativo, da qualidade de vida do indivíduo. Poluentes são agentes responsáveis pela poluição, como gases 
tóxicos na atmosfera, ruídos em excesso, detritos que sujam praias e rios e ainda cartazes publicitários que alteram as características visuais prejudicando a paisagem. A deterioração do meio ambiente, portanto, prejudica a qualidade de vida da coletividade (Petian, 2008).

Considera-se poluição sonora a emissão de ruídos indesejáveis de forma continuada e em desrespeito aos níveis legais que, dentro de um determinado período de tempo, ameaçam a saúde humana e o bem estar da coletividade (Sirvinskas, 2005).

Este tipo de poluição é produzido por ruídos aos quais o aparelho auditivo fica sujeito, e a velocidade que estes ruídos podem causar danos ao homem depende, além dos níveis de intensidade destes ruídos, de fatores como: tempo de exposição, condições gerais de saúde, idade, acústica do ambiente, entre outros. Quando combinados e ao longo do tempo de exposição, estes fatores podem produzir no homem efeitos como surdez, desequilíbrios psíquicos (como insônia ou até mesmo perda de capacidade intelectual) e muitas vezes complicações físicas no organismo (como o trauma acústico) (Pimentel - Souza, 1992).

\subsection{Ruídos e suas repercussões}

Existem dois fatores principais a serem distinguidos no ruído. O primeiro diz respeito à frequência, que consiste no número de vibrações por segundo emitidas pela fonte sonora, medida em $\mathrm{Hz}$, atribuindo aos ruídos a seguinte classificação: de baixa frequencia (graves) entre 20 a $300 \mathrm{~Hz}$; frequencias médias de 300 a $6.000 \mathrm{~Hz}$; altas frequencias (agudas) os de 6.000 a $20.000 \mathrm{~Hz}$. Os sons abaixo de $20 \mathrm{~Hz}$ são denominados de infra-sons e acima de $20.000 \mathrm{~Hz}$, de ultra-sons. Os sons de alta frequencia são mais nocivos à orelha humana e os ruídos de baixa frequencia, mesmo sendo suportáveis pela orelha, produzem efeitos orgânicos mais acentuados. O segundo a ser distinguido é a intensidade, medida em decibel - dB (A), considerando que os ruídos inferiores a $40 \mathrm{~dB}(\mathrm{~A})$ são apenas desagradáveis, enquanto os ruídos entre 40 - 90 dB (A) são capazes de favorecer distúrbios nervosos, e, os superiores a $90 \mathrm{~dB}$ agem de forma traumatizante na orelha (Faisal et al., 2008). 
A medicina preventiva considera o nível sonoro equivalente ( $L_{\text {eq }}$ ) de $65 \mathrm{~dB}$ (A), como o nível máximo ao qual o individuo pode se expor sem sofrer danos na saúde. Em níveis acima de $55 \mathrm{~dB}(\mathrm{~A})$ pode haver a ocorrência de estresse leve, acompanhado de desconforto. A partir de $70 \mathrm{~dB}$ (A) já ocorre desgaste do organismo, aumentando os riscos de infarto, acidente vascular cerebral, infecções, hipertensão arterial entre outras patologias. Á acima de $80 \mathrm{~dB}(\mathrm{~A})$ ocorre a liberação de endorfinas causando a sensação de prazer momentâneo. Após atingir $100 \mathrm{~dB}(\mathrm{~A})$ pode ocorrer o trauma auditivo e acarretar a surdez. No nível de $120 \mathrm{~dB}(\mathrm{~A})$ ocorre a lesão do nervo auditivo, provocando no mínimo zumbido constante nos ouvidos, tonturas e aumento do nervosismo. O ruído de $140 \mathrm{~dB}$ (A) pode ocasionar a destruição total do tímpano, provocando o que se denomina cestouro do tímpano (Belojevic, Jakvovlec, 1997; Maschke, 1999; WHO, 2003).

A OMS recomenda que em áreas residenciais o nível de ruído não ultrapasse o nível sonoro equivalente $L_{e q}=55 \mathrm{~dB}(A)$, para regiões como o centro da cidade o nível de referência é de $65 \mathrm{~dB}(\mathrm{~A})(\mathrm{WHO}, 2003)$.

Um dos maiores fatores etiológicos do ruído, nos grandes centros urbanos, consiste no tráfego de carros. Isso porque o ruído advém dos motores, dos choques entre as peças, do escapamento, do atrito do pneu com o asfalto, entre outros (Freitas, 2006).

Estudos realizados em várias cidades têm revelado que o ruído de tráfego é o maior contribuinte para os níveis sonoros medidos e a maior causa de incômodo em áreas urbanas (Fidel, 1978; Griffths et al., 1986; Maschke, 1999; Zannin et .al., 2001; Zannin et al., 2002; Zannin et al., 2003; Gerges, 2004).

Em média, pesquisas apontam que, em vias de trafego intenso os valores emitidos atinjam 75dB (A) (Zannin et al., 2001; Zannin et al., 2002).

São muitos os estudos que mostram a incidência dos efeitos danosos auditivos à exposição prolongada à ruídos excessivos, em especial sobre os trabalhadores de indústrias, construção civil e transporte público. Observando variação de 30 a $60 \%$ de acordo com o ramo de atividade (Andrade e Schochat 1988; Cordeiro et al. 1994; Horg e Raymond 2003).

Quando se pensa em danos à saúde, provocados pela emissão de ruídos intensos, a associação com danos auditivos é inevitável. Conforme Seligman 
(1997), os sintomas auditivos relacionados ao ruído assinalam em primeiro lugar à perda auditiva e dificuldades no entendimento da fala.

Para Melnick(1984) os efeitos do ruído na audição podem ser divididos em três categorias:

- Mudança temporária no limiar (TTS - Temporary Threshold Shift) - é uma diminuição gradual da sensibilidade auditiva com o tempo de exposição a um ruído contínuo e intenso.

- Trauma acústico - essa expressão deve ser restrita ao resultado de uma exposição isolada a um ruído de grande intensidade, considerados os mais nocivos ao ouvido humano, por produzirem lesões mecânicas irreversíveis na cóclea.

- Perda Auditiva Induzida por Ruído (PAIR) - É uma mudança dos limiares auditivos que ocorre, em geral, após vários anos de exposição à ruídos de intensidade excessiva. A perda é neurossensorial, geralmente bilateral, irreversível e progressiva com o tempo de exposição ao ruído.

Alguns fatores podem facilitar a perda auditiva por ruídos como: idade, prematuridade, sexo masculino, diferenças raciais, drogas e agentes químicos, tempo e intensidade da exposição (Henderson et al, 1993).

$\mathrm{Na}$ faixa de frequências baixas, a partir das frequências infra-sônicas (< $20 \mathrm{~Hz}$ ), os prejuízos predominantes são enjoos, vômitos, tonturas. Nas frequências agudas podemos encontrar alterações na atenção e concentração mental, no ritmo respiratório, ritmo cardíaco, aumento da irritabilidade, perda de apetite e estados pré-neuróticos (Colleoni e Cols, 1981).

Dani e Garavelli (2001), complementam os desconfortos causados pela exposição à ruídos intensos e excessivos, quando é possível encontrar sintomas como: fadiga, perturbação do sono, problemas cardiovasculares, como a hipertensão arterial sistêmica, estresse, alergias, distúrbios digestivos, úlceras, falta de concentração, prejudicando o desempenho funcional.

O estímulo auditivo, antes de chegar ao córtex cerebral, passa por inúmeras estações subcorticais, principalmente pelas funções vegetativas, o que explica a presença dos efeitos não-auditivos induzidos pelo ruído (Teixeira et al., 2011). 
Reações psíquicas como a motivação e a disposição podem ser modificadas negativamente através do ruído. O nervosismo e a agressividade aumentam e a capacidade de aprendizagem e a concentração são sensivelmente afetadas. Em ambientes industriais isso pode levar à redução da capacidade de trabalho, à diminuição da capacidade de percepção, aumentando assim a probabilidade de ocorrência de acidentes (Suter, 2002).

Em estudos submetendo indivíduos adultos jovens a provas de habilidade foi demonstrado que com a exposição ao ruído contínuo ocorre a diminuição do rendimento e eficiência, elevando o número de erros e um provável aumento de acidentes. Deste modo, atividades que exigem alto grau de atenção ou processamento de informações, são afetadas pela poluição sonora (Hsu et al., 2008; Siu et al., 2010).

O ruído induzido pode alterar funções de equilíbrio, porém poucos estudos são focados na relação entre sinais estabilométricos e a estimulação vestibular, devido à dificuldade na obtenção de uma estimulação específica e independente deste sistema. Mainent et al., (2007) realizaram um estudo, em indivíduos na faixa etária de 25 anos, que procurou analisar este aspecto, propondo sons de alta intensidade como uma forma de perturbar o sistema vestibular, com base na teoria do potenciais evocados vestibulares miogênicos. Não houve diferença estatística entre as condições com e sem estimulação sonora. Entretanto, a análise visual do gráfico de deslocamento lateral médio, ântero-posterior e desvio padrão mostraram alguns padrões consistentes de mudança durante a fase de recuperação após a estimulação. Tendo estimulado experimentos com maiores intensidades, bem como outras fontes de estímulo que poderiam afetar os receptores vestibulares, para procurar modificações específicas no sinal de força.

Ao correlacionar o ruído com sintomas vestibulares foi verificado que durante a exposição ao ruído ou mesmo após, muitos pacientes apresentaram alterações tipicamente vestibulares, descritas como vertigens, que podem ou não ser acompanhadas de naúseas, vômitos, suores frios, dificuldade no equilíbrio e na marcha, nistagmo, síncopes e dilatação das pupilas. Porém alguns indivíduos, mesmo expostos a ruídos, podem não se queixar dos sintomas relatados acima, isso ocorre devido a uma grande capacidade do 
sistema vestibular de se adaptar ao dano gradativo imposto pelos sons de alta intensidade. Este fato indica que é possivel ocorrer modificações das estruturas labirínticas sem a existência de muitas queixas, provavelmente devido a uma grande capacidade do aparelho vestibular em se adaptar ao dano promovido por sons de altas intensidades (Laitinen, 2005; Mendes et al., 2007; Milonski et al, 2007; Costa et al., 2009).

Dessa forma podem ocorrer alterações importantes nas estruturas labirínticas sem que isso se reflita em sintomatologia por parte dos indivíduos. Diante das vulnerabilidades do envelhecimento a ocorrência de alterações pode ser mais evidente.

\subsection{Ruídos e Envelhecimento}

A presbiacusia é definida como uma perda auditiva neurossensorial, com o grau podendo variar de leve a profundo tanto nas frequências baixas quanto nas frequências altas, apresenta início gradual e progressivo, de forma simétrica, descendente e bilateral para sons em frequências altas $(3000 \mathrm{a} 8000 \mathrm{~Hz})$, muitas vezes acompanhada por dificuldades no reconhecimento de fala (Souza e Russo, 2009; Calais et al., 2008).

Os idosos apresentam como principais sintomas da presbiacusia: dificuldade em participar de conversas ou de falar ao telefone, em compreender as palavras, em localizar uma fonte sonora, em ouvir alarmes, telefone, campainha da porta, veículos se aproximando e necessidade de aumentar o volume da televisão ou rádio (Baraldi et al., 2007).

Russo (1999) ressalta que a intolerância a sons de grande intensidade é outra queixa bastante frequente, indicando a presença de recrutamento, principalmente nas lesões sensoriais. O recrutamento é definido como um aumento desproporcional da sensação de intensidade em relação ao aumento da intensidade física, implicando em uma redução do campo dinâmico da audição. Alerta ainda, que a diferença em que o indivíduo detecta em seu limiar auditivo mínimo e o que ele tolera em seu limiar de desconforto é bastante reduzida. Isto significa que, quando os outros falam em intensidade fraca, 0 idoso não consegue ouvir e compreender a mensagem falada, mas ao elevarem 
a intensidade da voz, atingem o nível de desconforto do idoso, o qual tende a declarar com irritação: "não grite, pois eu não sou surdo".

Mesmo com esse prejuízo auditivo ocasionado pelo processo do envelhecimento, os malefícios do ruído parecem atingir de forma expressiva essa população. Sorensen et al., (2011) observaram em uma população de 50 mil pessoas que a cada $10 \mathrm{~dB}(\mathrm{~A})$ de ruído no trânsito aumenta o risco de acidente vascular encefálico em 14\%, em média, em todos os grupos etários. Para aqueles abaixo dos 65 anos, o risco não foi estatisticamente significativo. Mas a probabilidade aumentou enormemente no grupo de pessoas com mais de 65 anos, aumentando 27\% para cada $10 \mathrm{~dB}(\mathrm{~A})$ a mais de ruído. Acima de $60 \mathrm{~dB}$ (A), o risco de acidente vascular foi ainda maior.

Existem poucos estudos que analisam os efeitos das alterações ambientais atuais sobre o desempenho funcional de idosos. Os efeitos dos ruídos, como os provocados pela poluição sonora, são pouco discutidos, especificamente nessa população. Principalmente no que se refere aos efeitos extra auditivos e agudos.

Os trabalhos que se destinam a verificar o impacto da poluição sonora em sua grande maioria avaliam indivíduos jovens e tem como desfecho a perda auditiva por estimulação crônica. Mesmo os estudos que apontam uma incidência elevada de comprometimento auditivo nos idosos, afirmam que tal alteração se dá em decorrência da exposição crônica a ruídos intensos, muitas vezes desde a faixa etária de adulto jovem, não detalhando os efeitos da exposição aguda sobre sua funcionalidade. É possível que condições ambientais que imponham sobrecargas fisiológicas e psicológicas, como a poluição sonora, possam também afetar a funcionalidade dos idosos.

Sobre esta óptica criou-se o raciocínio que fundamenta a nossa hipótese: $\mathrm{O}$ ruído sonoro provoca alteração no desempenho funcional em idosos.

A escolha das áreas da cognição, força muscular e equilíbrio deu-se pelos seguintes motivos:

- Primeiro por estarem envolvidas praticamente em todas as atividades do dia a dia de uma pessoa com vida independente, podendo as alterações nestas áreas ter impacto direto na qualidade de vida.

- Segundo porque mudanças pequenas nessas funções podem ser mensuráveis objetivamente através de testes. Em último, mas não menos 
importante, porque sabidamente a senescência determina alterações na função cognitiva, de força muscular e equilíbrio, levando a perda de reserva funcional e maior susceptibilidade às agressões, de modo que um estímulo pouco danoso para um jovem pode acarretar prejuízos objetivos a indivíduos idosos. 


\section{OBJETIVOS}

\section{OBJETIVO PRIMÁRIO}

Avaliar o impacto dos ruídos sonoros no desempenho funcional de idosos da comunidade.

\section{OBJETIVOS SECUNDÁRIOS}

- Avaliar os efeitos dos ruídos sonoros nas funções cognitivas de idosos da comunidade;

- Avaliar os efeitos dos ruídos sonoros no equilíbrio postural de idosos da comunidade;

- Avaliar os efeitos dos ruídos sonoros nas funções motoras de idosos da comunidade. 


\section{MÉTODOS}

\subsection{Seleção da amostra}

Foram selecionados 20 idosos saudáveis, de ambos os sexos, com idades de 60 a 80 anos do Ambulatório do Serviço de Geriatria do Hospital das Clínicas da Faculdade de Medicina da Universidade de São Paulo (HCFMUSP).

Critérios clínicos para inclusão:

- Pontuação no Mini Exame do Estado Mental (MEEM), dentro da normalidade para a escolaridade;

- Ausência de sintomas depressivos;

- Alfabetizados;

- Função visual que possibilite a realização dos testes;

- Função auditiva que possibilite a realização dos testes, com ausência de comprometimento ou de suspeita de prejuízo auditivo;

- Equilíbrio que possibilite a realização dos teses;

- Concordância em participar do estudo, assinando o Termo de Consentimento Livre e Esclarecido (Anexo A).

Critérios clínicos para exclusão:

- Uso de 5 medicamentos ou mais;

- Ingerir bebida alcoólica habitualmente;

- Doença sistêmica descompensada ou sintomática.

A avaliação inicial, para seleção e admissão dos sujeitos da pesquisa, consistiu de anamnese, exame físico e funcionalidade, rastreamento cognitivo, investigação de sintomas depressivos, déficits de equilíbrio e auditivos.

Visando averiguar a suspeita ou presença de déficit cognitivo, foi utilizada a pontuação no Mini Exame do Estado Mental (Folstein et al., 1975). Os valores de referência, segundo a escolaridade foram os preconizados por Bertolucci et al., (2003) (Anexo B).

Para a exclusão por presença sintomas depressivos foi utilizada a pontuação superior a 5 na Escala de Depressão Geriátrica (GDS), na sua versão curta, com 15 questões (Sheikh e Yesavage, 1986) (Anexo C) . 
Para verificar a presença de déficit de equilíbrio prévio e limitante ao uso da plataforma foi aplicado o Short Physical Performance Battery (SPPB) (Guralnik, 1994). Indivíduos que apresentaram pontuações inferiores a 7 , indicando um baixo desempenho foram excluídos do estudo (Anexo D).

\subsection{METODOLOGIA}

Foi realizado um estudo experimental com indivíduos idosos submetidos à emissão sonora de ruídos intensos, simulando a poluição sonora encontrada nos centros urbanos. Nestas condições realizaram os testes de funcionalidade.

Os idosos participantes do estudo foram submetidos à randomização permutada em blocos a cada dois participantes em dois grupos, o grupo A que realizou a primeira avaliação sem estimulação sonora $(n=10)$ e o grupo $B$ que realizou a primeira avaliação com estimulação sonora $(n=10)$. Esta divisão visou minimizar o efeito de aprendizagem que pode ser encontrado na repetição do teste.

Os pacientes selecionados responderam a um protocolo de avaliação clínica inicial, contendo perguntas sobre dados socioeconômicos e hábitos como tabagismo, etilismo, frequência com que sai de casa e prática de atividade física (Anexo E).

Após a seleção inicial, os voluntários foram submetidos aos testes de memória e cognição do protocolo por duas vezes. A primeira avaliação cognitiva computadorizada (T1) tinha como objetivo realizar a apresentação dos testes, sendo os mesmos reaplicados (T2), na mesma sequência, após o término da primeira bateria. O tempo utilizado para realização de cada bateria foi de aproximadamente 30 minutos.

Após sete dias da seleção e treinamento, cada voluntário realizou duas sessões de testes de cognição, equilíbrio e força muscular (Quadro 1). Os indivíduos do grupo A realizaram a segunda sessão sob estimulação sonora, os indivíduos do grupo B realizaram a segunda avaliação sem a estimulação sonora. Ambas as avaliações foram realizadas no mesmo dia.

O tempo utilizado para realização do protocolo em cada uma das sessões foi de aproximadamente 45 minutos. 
Quadro 1 - Protocolo Experimental.

1.Medidas de sinais vitais pré exposição - frequência cardíaca e respiratória, pressão arterial.

2. Aplicação de testes cognitivos

3. Aplicação de testes de equilíbrio na plataforma de força

4. Aplicação de teste de força de preensão manual (handgrip) - três tentativas

Antes do início da sessão foram medidos: frequência cardíaca (contagem do pulso radial), pressão arterial (medida não invasiva) e frequência respiratória.

Todos os participantes do estudo realizaram os testes cognitivos, de equilíbrio e de força muscular em uma sala isolada, com e sem a estimulação sonora visando a comparação das performances.

A estimulação sonora, utilizada em uma das sessões de testes, foi proveniente de uma gravação simulando a poluição sonora de grandes centros urbanos, com simulação de motores de carros, atrito dos pneus com o asfalto, buzinas, sirenes, obras em vias públicas entre outros ruídos descontínuos. A reprodução desta gravação foi realizada com auxílio de um aparelho sonoro portátil. A intensidade da emissão de ruídos foi verificada através do decibilímetro e padronizada entre 75 e $80 \mathrm{~dB}(\mathrm{~A})$. A frequencia sonora aplicada no testes foi aleatória e flutuante afim de não causar acomodação.

A aplicação dos testes de cada sessão respeitou a ordem, inicialmente avaliação cognitiva, em seguida o teste de equilíbrio e finalizando com a medida de força com o dinamômetro.

Após a realização dos testes sob estimulação sonora e sob ambiente controlado foi aplicado um breve questionário sobre conforto sonoro (Anexo F).

\subsection{Avaliação Cognitiva}

Para avaliar a função cognitiva foi aplicada uma série de testes computadorizados desenvolvido por neurocientistas das Universidades de Stanford, Califórnia, São Francisco e McGill (Sternberg et al., 2013). A série constitui-se de testes simples e rápidos realizados no próprio computador, 
portanto não requer qualquer conhecimento prévio ou noção de informática. Encontra-se disponível para a população na rede da internet, mediante assinatura. Foi-nos concedida, pelos idealizadores do site, uma licença para utilização em nosso estudo. Para facilitar a realização dos testes, utilizamos um notebook com função touchscreen, ou seja, a ativação dos comandos pode ser dada pelo simples toque da tela (Anexo G).

Os testes aplicados foram:

- Trial Making A: avalia a atenção e a velocidade na realização da tarefa. É composto de 25 círculos numerados de 1 a 25, distribuídos ao acaso. Ao voluntário é solicitado que ative com o toque os círculos na ordem crescente dos números. Ao tocar o círculo na ordem correta, ele muda de cor indicando que o paciente pode prosseguir com a tarefa. Caso a sequência escolhida esteja errada, aparece um " $x$ " sobre o número e possibilita que o paciente escolha outra opção. O tempo para a realização do teste foi avaliado (Figura $1)$.

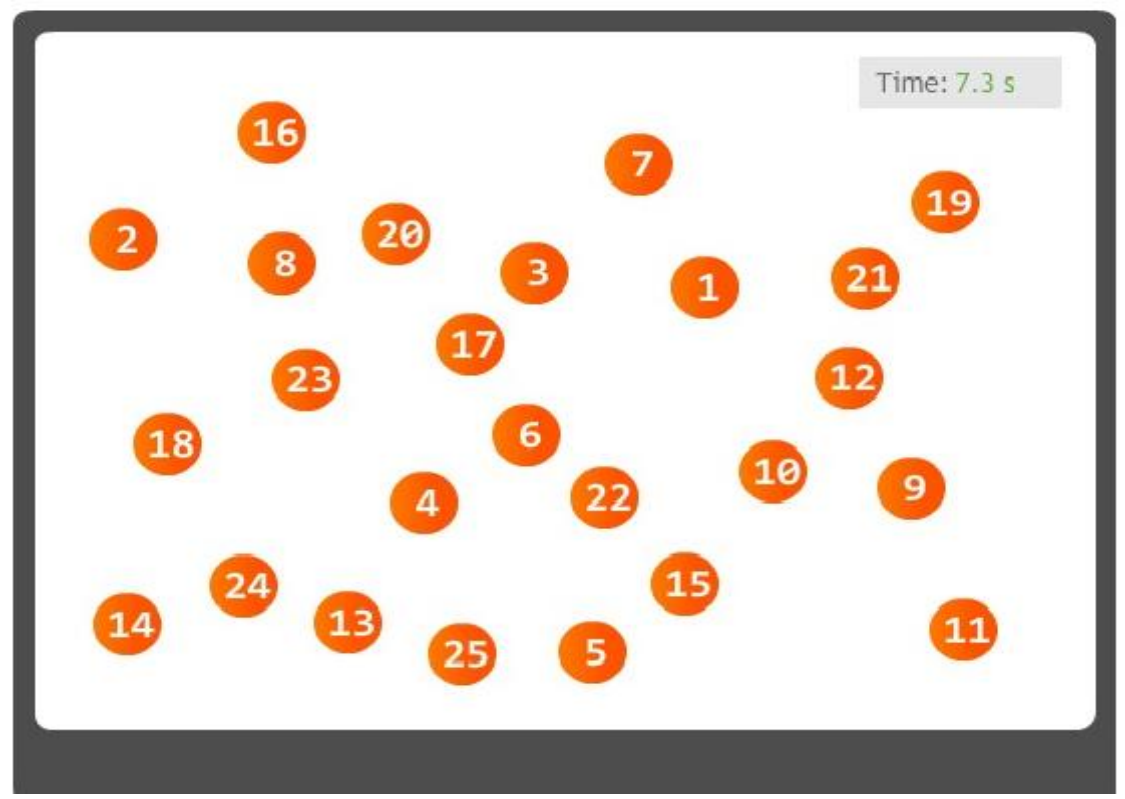

Figura 1. Tela inicial do teste Trail Making A do site Lumosity

- Trial Making B: avalia a atenção e a velocidade na realização da tarefa. É composto de 25 círculos contendo 13 números e 12 letras, distribuídos ao acaso. Ao voluntário é solicitado que ative com o toque os círculos na ordem crescente dos números e ordem alfabética das letras de forma alternada ( $1 \mathrm{~A}$, 
2B, 3C). Ao tocar o círculo na ordem correta, ele muda de cor indicando que o paciente pode prosseguir com a tarefa. Caso a sequência escolhida esteja errada, aparece um " $X$ " sobre o número e possibilita que o paciente escolha outra opção. O tempo para a realização do teste foi avaliado (Figura 2).

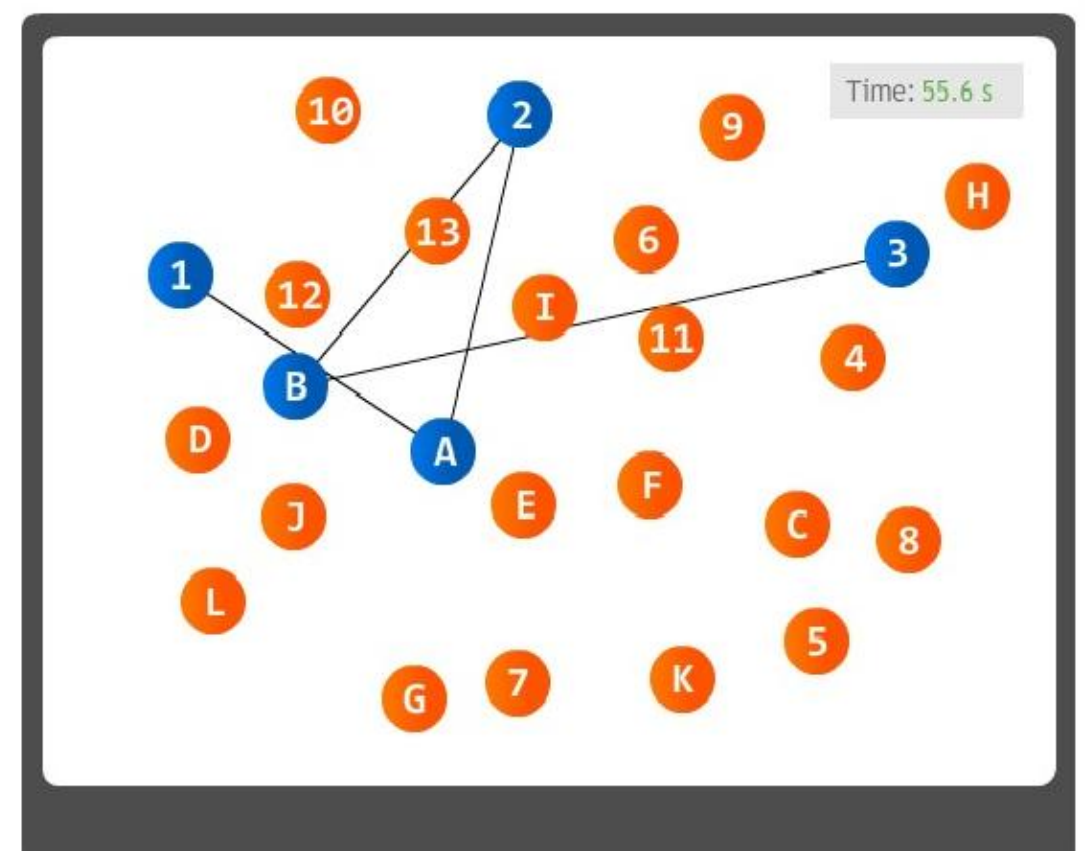

Figura 2. Tela do teste Trail Making B, em andamento, do site Lumosity

- Spatial Recognition: avalia o reconhecimento espacial durante a realização da tarefa. O teste consiste na visualização individual de 5 quadrados de cor e tamanhos iguais em determinadas posições na tela. Foi solicitado que o paciente memorizasse a posição dos quadrados. Após esta etapa, apareceram 2 quadrados ao mesmo tempo, um na mesma posição visualizada anteriormente e um em uma nova posição. $O$ voluntário teve que indicar o quadrado que ocupava a posição já visualizada. Neste teste foi avaliado o número de acertos (Figura 3). 

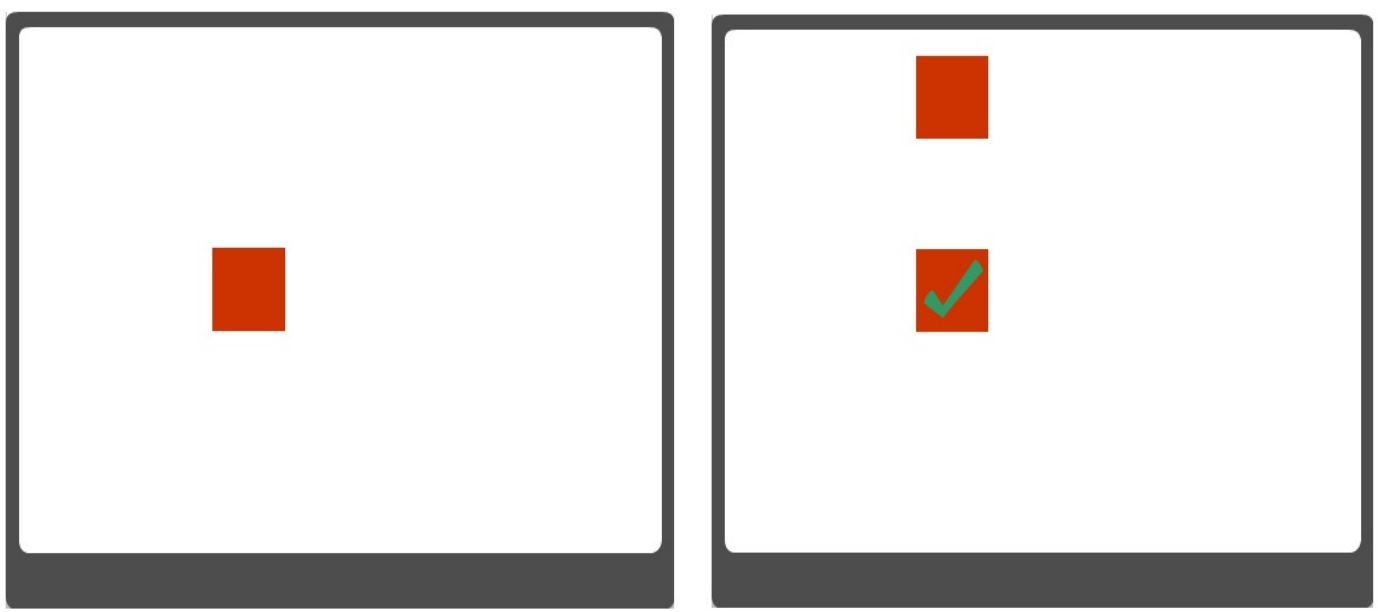

Figura 3. Tela inicial e final do teste Spatial Recognition, do site Lumosity

- Go/No-Go: avalia o tempo de reação mediante a variação de estímulos visuais. O teste consiste na apresentação de uma figura de uma determinada fruta e foi explicado para o voluntário que ele deveria acionar a tecla espaço o mais rápido possível toda vez que visualizasse a figura da fruta apresentada. Após esta etapa, o computador mostrou uma sequência de imagens de frutas, incluindo a fruta inicialmente demonstrada. Neste teste foi avaliado o tempo de reação e o número de erros (Figuras 4 e 5).

Respond as quickly as possible by pressing Space each time you see this fruit. Do NOT press Space if you see a different fruit. We'll start with some practice.

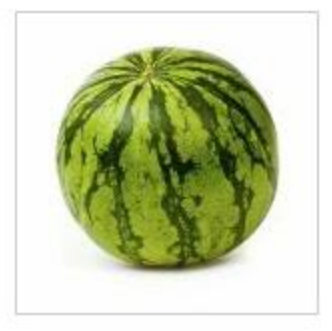

\section{Start Practice}

Figura 4. Tela inicial do teste Go /No-Go do site Lumosity 


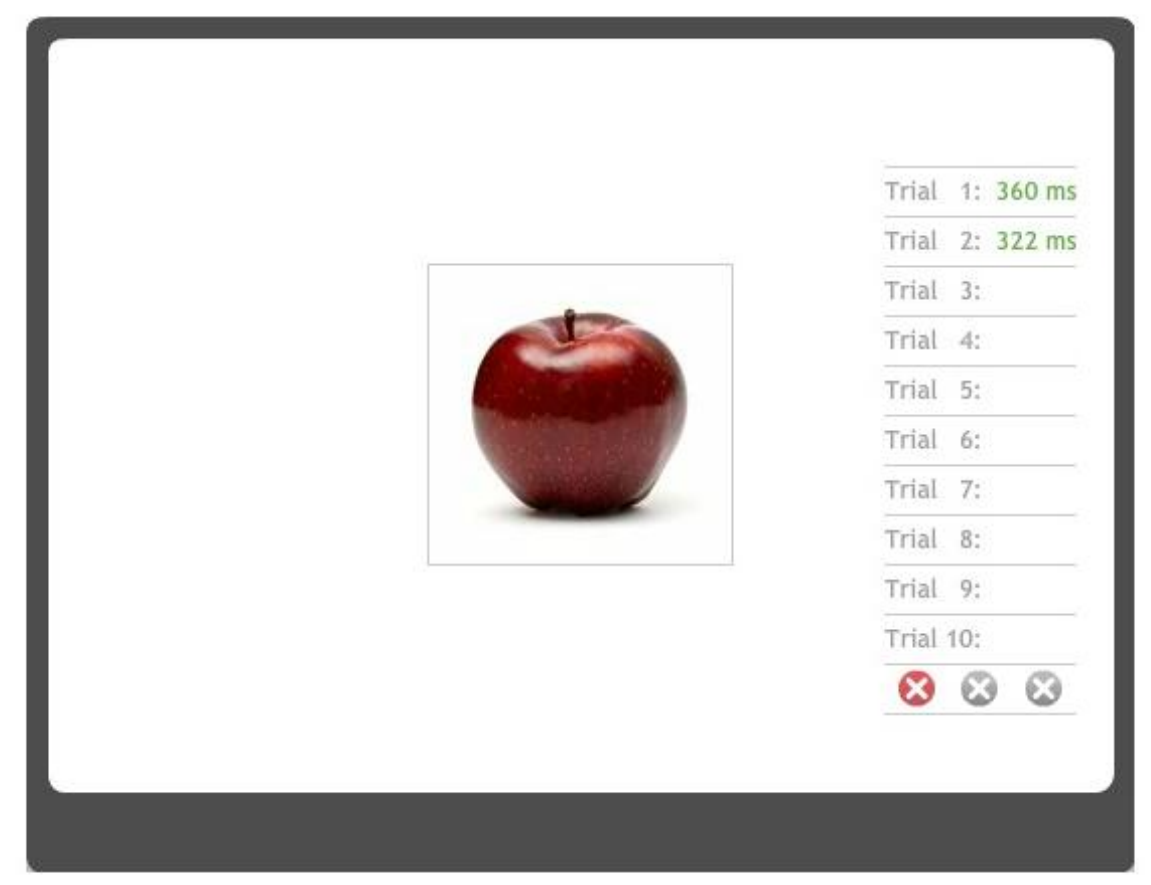

Figura 5. Tela da teste Go/No-Go em andamento, do site Lumosity

- Pattern Recognition: avalia a memorização de detalhes e orientações de figuras. O teste consiste na apresentação de 12 imagens simples, com características geométricas, de forma sequencial. Foi solicitado que memorizasse as imagens, atentando aos detalhes e posicionamento correto. Após esta etapa, foram apresentadas em pares, figuras semelhantes, sendo uma visualizada anteriormente e a outra inédita. Cabia ao voluntário indicar a figura já observada. Neste teste foi avaliado o total de acertos (Figura 6).
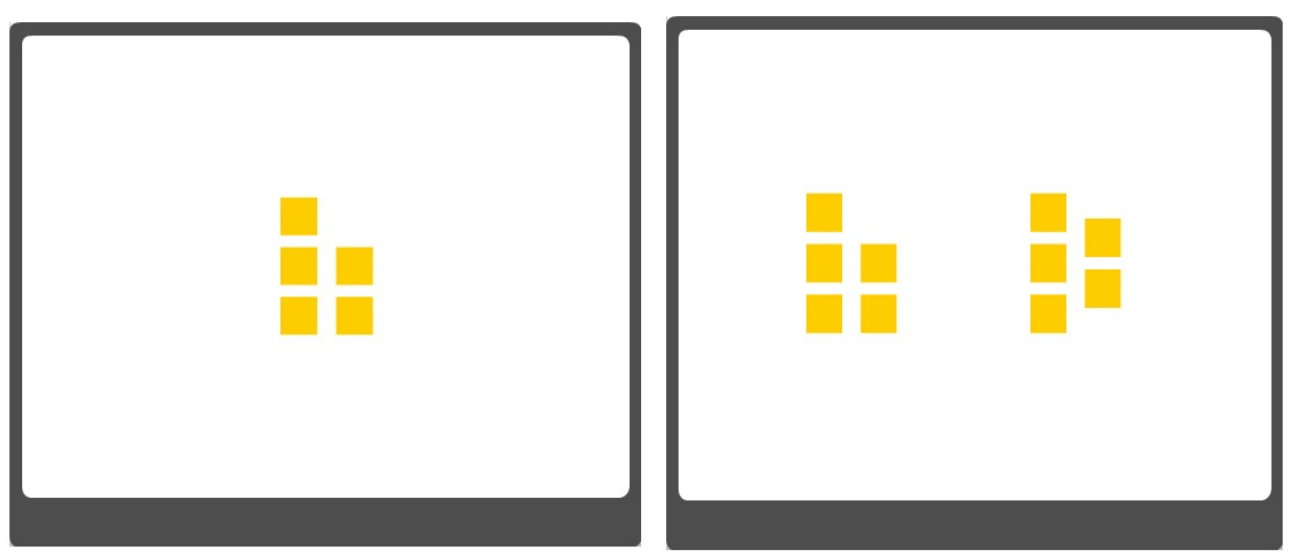

Figura 6. Tela inicial e final do teste Pattern Recognition do site Lumosity 
- Memory Span: avalia a memória espacial durante a realização da tarefa. O teste consiste na apresentação de 10 cartões simultâneos na tela. Esses cartões mudaram de cor individualmente em uma sequência. Cabe ao voluntário memorizar a ordem de ativação dos cartões e reproduzir corretamente, na mesma sequência apresentada, na tela do computador. $O$ número de cartões ativados aumenta a cada duas rodadas, iniciando com dois cartões. Caso o voluntário errasse a sequência por duas vezes com o mesmo número de cartões o teste se encerrava. Neste teste foi avaliado o número de sequências corretas.

- Reverse Memory Span: avalia a memória espacial durante a realização da tarefa. O teste consiste na apresentação de 10 cartões simultâneos na tela. Esses cartões mudaram de cor individualmente em uma sequência. Cabia ao voluntário memorizar a ordem de ativação dos cartões e reproduzir corretamente, na sequência inversa, na tela do computador. O número de cartões ativados aumentava a cada duas rodadas, iniciando com dois cartões. Caso o voluntário errasse a sequência por duas vezes com o mesmo número de cartões o teste se encerrava. Neste teste foi avaliado o número de sequências corretas (Figura 7).

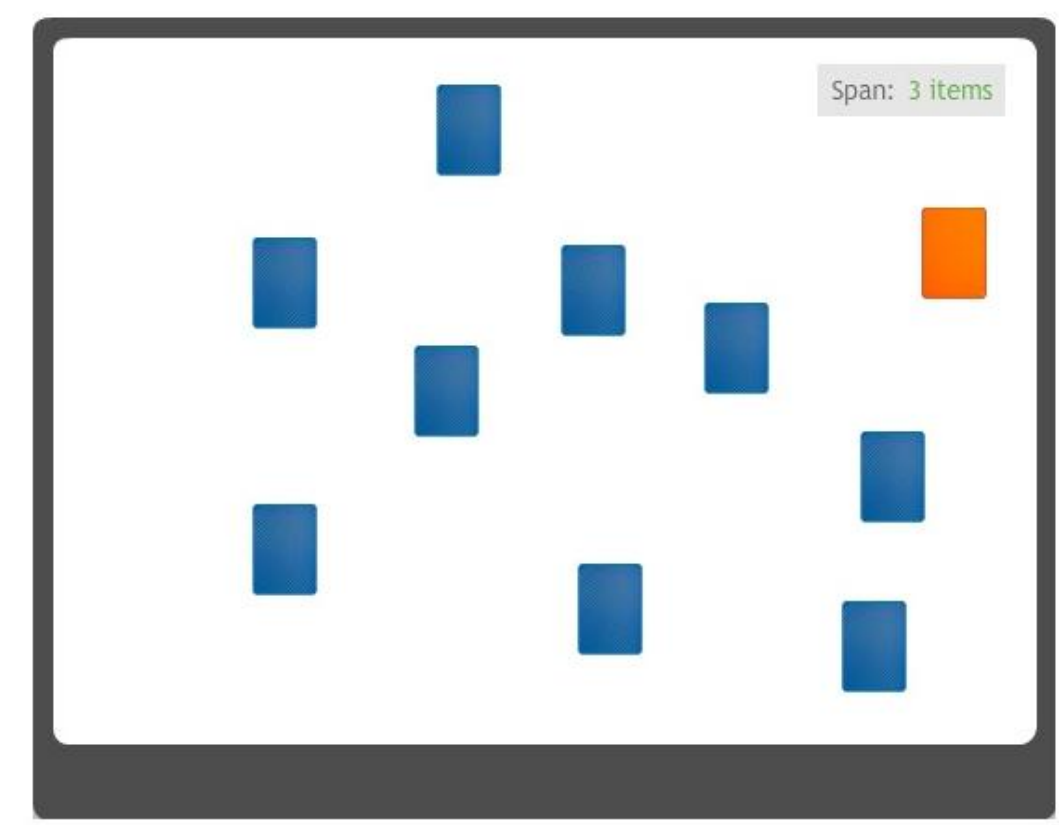

Figura 7. Tela inicial do teste Memory Spam e Reverse Memory Spam do site Lumosity 
Foram aplicados outros dois testes adaptados do programa anterior.

- Digit Span: avalia a memória de trabalho durante a realização da tarefa. O teste consiste em uma apresentação numérica, aleatória e individual oral. Cada algarismo foi apresentado com intervalo de 1 segundo. O início da sequência apresentava um número de 2 algarismos. Cabia ao voluntário repetir a ordem numérica apresentada. A cada sequência correta, uma nova era criada, acrescentando mais um algarismo. Caso o voluntário errasse a sequência, uma outra era apresentada contendo o mesmo número de dígitos. Se o erro persistisse o teste se encerrava. Neste teste foi avaliado o número de sequencias corretas.

- Reverse Digit Span: avalia a memória de trabalho e reordenação durante a realização da tarefa. O teste consiste em uma apresentação numérica, aleatória e individual oral. Cada algarismo foi apresentado com intervalo de 1segundo. Iniciamos a sequência apresentando um número de 2 algarismos. Cabia ao voluntário repetir inversamente a ordem numérica apresentada. A cada sequência correta, uma nova era criada, acrescentando mais um algarismo. Caso o voluntário errasse a sequência, uma outra era apresentada contendo o mesmo número de dígitos. Se o erro persistisse 0 teste se encerrava. Neste teste foi avaliado o número de sequências corretas.

\subsection{Avaliação do Equilíbrio}

A avaliação do equilíbrio foi realizada utilizando-se uma plataforma de força (Basic Balance System - NeuroCom) (Figura 8). Os testes aplicados foram o teste clínico modificado de interação sensorial sobre o equilíbrio (modified Clinical Test of Sensory Interaction on Balance - mCTSIB) e o teste de Limites de Estabilidade (LoS - Limits of Stability test). 

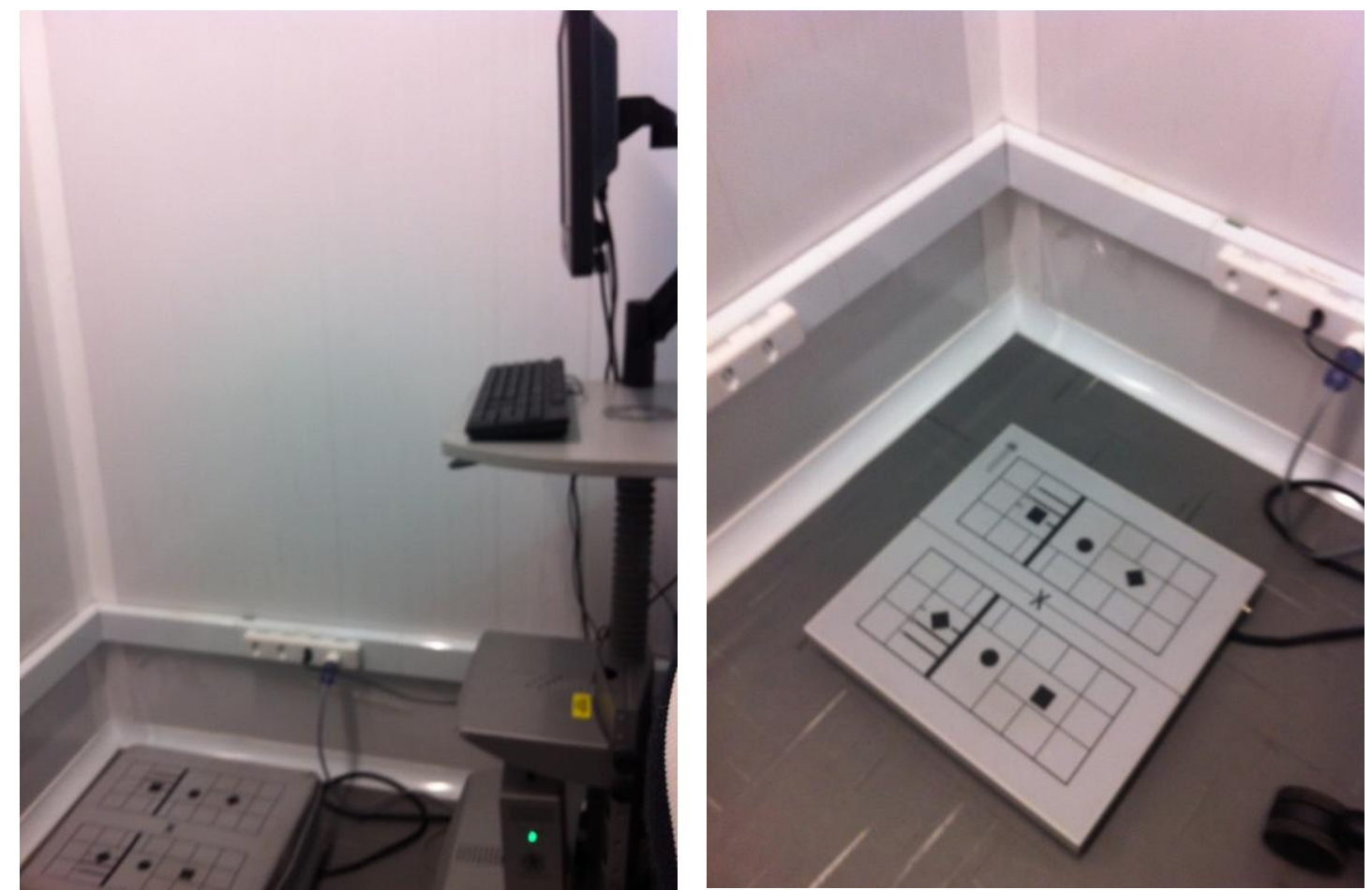

Figura 8. Plataforma de força (Basic Balance System - NeuroCom)

\subsection{1 mCTSIB}

O mCTSIB é uma forma simplificada do teste de organização sensorial (Sensory Organization Test - SOT) que é realizado na posturografia computadorizada. O teste avalia o controle do equilíbrio e quantifica a velocidade das oscilações durante 4 condições sensoriais (em pé) :

1)olhos abertos superfície firme

2)olhos fechados superfície firme

3)olhos abertos superfície instável (espuma)

4)olhos fechados superfície instável (espuma)

Em cada uma dessas condições o indivíduo deve permanecer descalço, com os pés posicionados em uma das três posições recomendadas pelo fabricante e com os braços estendidos ao longo do corpo. O tempo de cada tarefa é 10 segundos. São registradas 3 tentativas. A espuma utilizada nas posições 3 e 4 foi fornecida pelo fabricante, possui 45 com de largura e comprimento, $12 \mathrm{~cm}$ de altura e uma densidade de $0,5 \mathrm{~kg} / \mathrm{m}^{3}$.

O relatório do mCTSIB fornece o traçado de cada tentativa junto com um valor numérico que indica a velocidade da oscilação em graus por segundo e a 
duração total de cada tentativa. Um gráfico fornece a velocidade média de oscilação do CG para cada condição e um número composto das 3 tentativas. $O$ alinhamento do $C G$ em cada situação é também demonstrado graficamente.

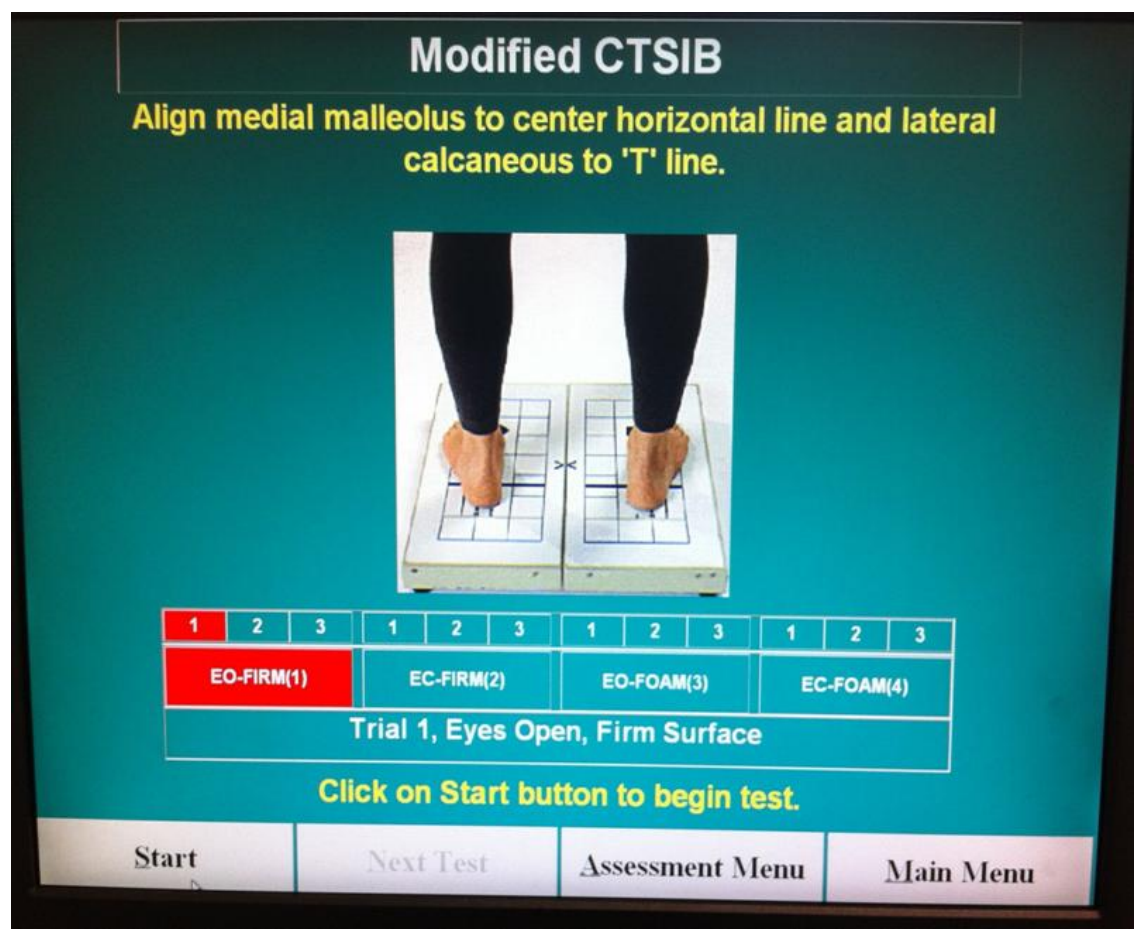

Figura 9. Tela do teste clínico modificado de interação sensorial sobre o equilíbrio (modified Clinical Test of Sensory Interaction on Balance - mCTSIB) da plataforma de força (Basic Balance System - NeuroCom)

\subsubsection{LoS - Limits of Stability test}

A bateria de teste do LoS requer que o indivíduo inicie um movimento. $O$ grau de oscilação indica quão longe o CG pode ser movido ao redor da base de suporte enquanto a estabilidade é mantida.

A prova dos limites de estabilidade analisa o deslocamento voluntário do centro de gravidade do individuo em 8 direções (anterior, anterior direita e esquerda, direita, posterior direita e esquerda e posterior). O sujeito é colocado na plataforma em bipedestação diante da tela, com os calcanhares e os pés em três possibilidades de posições, como orienta o fabricante. O sujeito visualiza seu centro de gravidade na tela e o posiciona no centro, exatamente sobre sua 
base de suporte, utilizando a representação instantânea que a tela apresenta. Após comando audiovisual, desloca seu centro de gravidade em direção a determinado alvo até o máximo que for capaz - sem mover os pés. Aparecerá no monitor um cursor que representa o centro de gravidade. $O$ indivíduo deve mover seu Centro de Pressão (CP) no sentido horário até alcançar os alvos nas 8 posições descritas.

Além de avaliar cada uma das oito direções realizadas, o equipamento calculou uma composição que expressa quatro das direções cardiais: anterior, posterior, lateral direita e lateral esquerda, e consideramos a composição dos dados na direção frontal.

O cálculo do teste é teórico e realizado pelo programa Balance Master, calculando o valor esperado de cada varável considerando a altura de cada indivíduo. Considerando que o Centro de Massa (CDM) está posicionado a 2,3ํㅜำ a diante da linha vertical que passa pelos maléolos e a uma altura de 55,27\% da altura do individuo (NeuroCom International Inc. 2002).

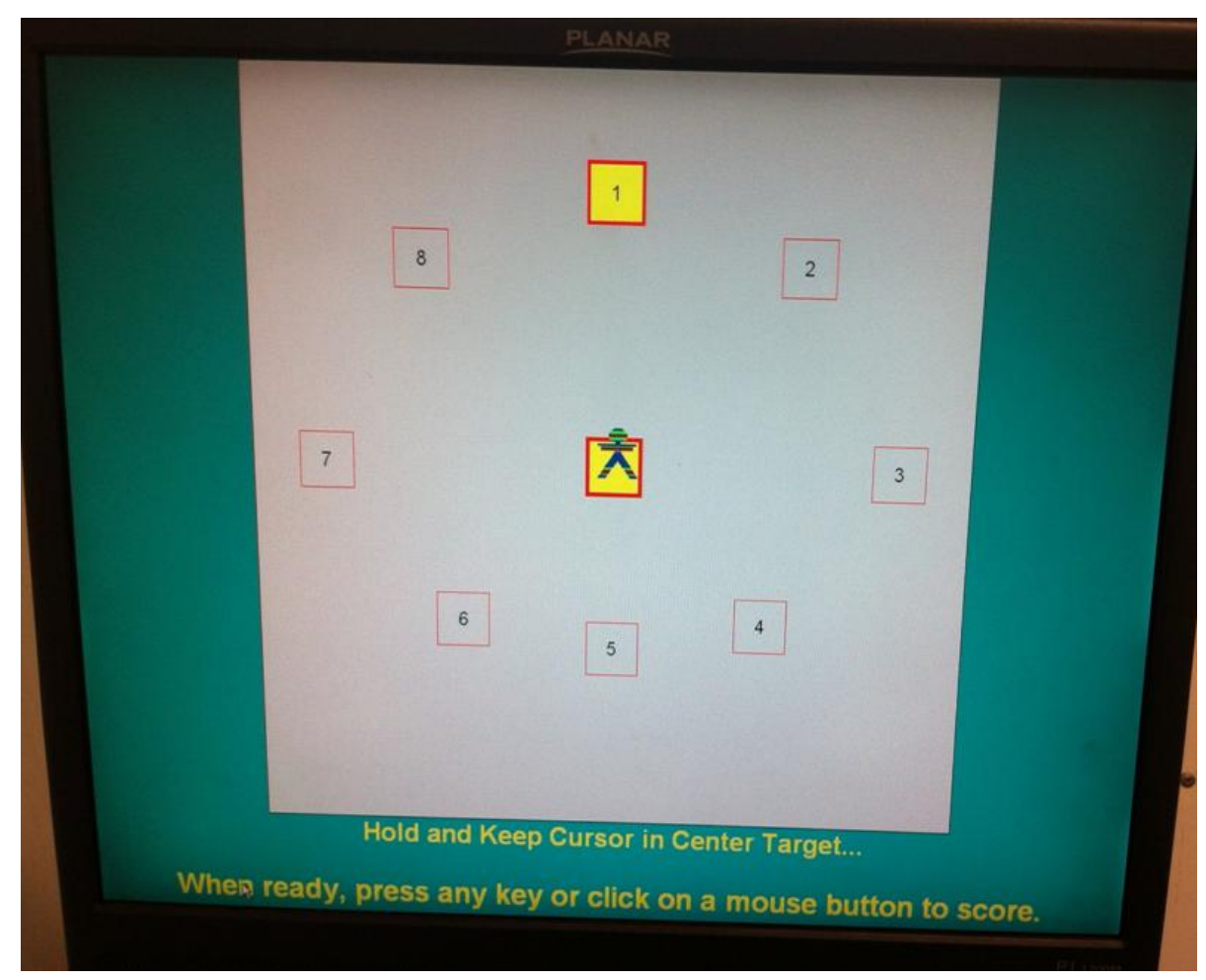

Figura 10. Tela do teste de Limites de Estabilidade (LoS - Limits of Stability test) na plataforma de força (Basic Balance System - NeuroCom) 
O testes produzem as seguintes variáveis sobre o indivíduo:

1) Tempo de Reação em segundos, correspondendo ao tempo gasto para iniciar o movimento em busca de um dos 8 alvos, após o comando audiovisual do computador. Valores mais baixos indicam desfecho positivo. Valores normais para a idade $<1.05 \mathrm{~s}$

2) Velocidade do Movimento, em graus por segundo, representada pela velocidade média de deslocamento do CG para cada um dos 8 alvos, durante os 8 segundo de teste. Valores mais baixos indicam desfecho positivo. Valores normais para a idade $>3,5 \% / \mathrm{s}$

3) Ponto Final de Excursão, dado em porcentagem percorrida em relação a distancia total necessária para alcançar o alvo. É a maior distancia alcançada pelo CG na primeira tentativa, sendo ignorados os ajustes feitos após o primeiro movimento. Valores mais baixos indicam desfecho positivo. Valores normais para a idade $>69 \%$.

4) Excursão Máxima, expressa em porcentagem do limite de estabilidade teórico, é a maior distancia alcançada pelo CG para alcançar o alvo durante o tempo de teste. Nesta varável é levado em conta os ajustes realizados após o primeiro movimento. Valores mais baixos indicam desfecho positivo. Valores normais para a idade $86,8 \%$.

5) Controle de Direção, expresso em porcentagem, é a porcentagem de permanência do CG na linha traçada como o deslocamento ideal. Valores mais baixos indicam desfecho positivo. Valores normais para a idade $>75,3 \%$. 


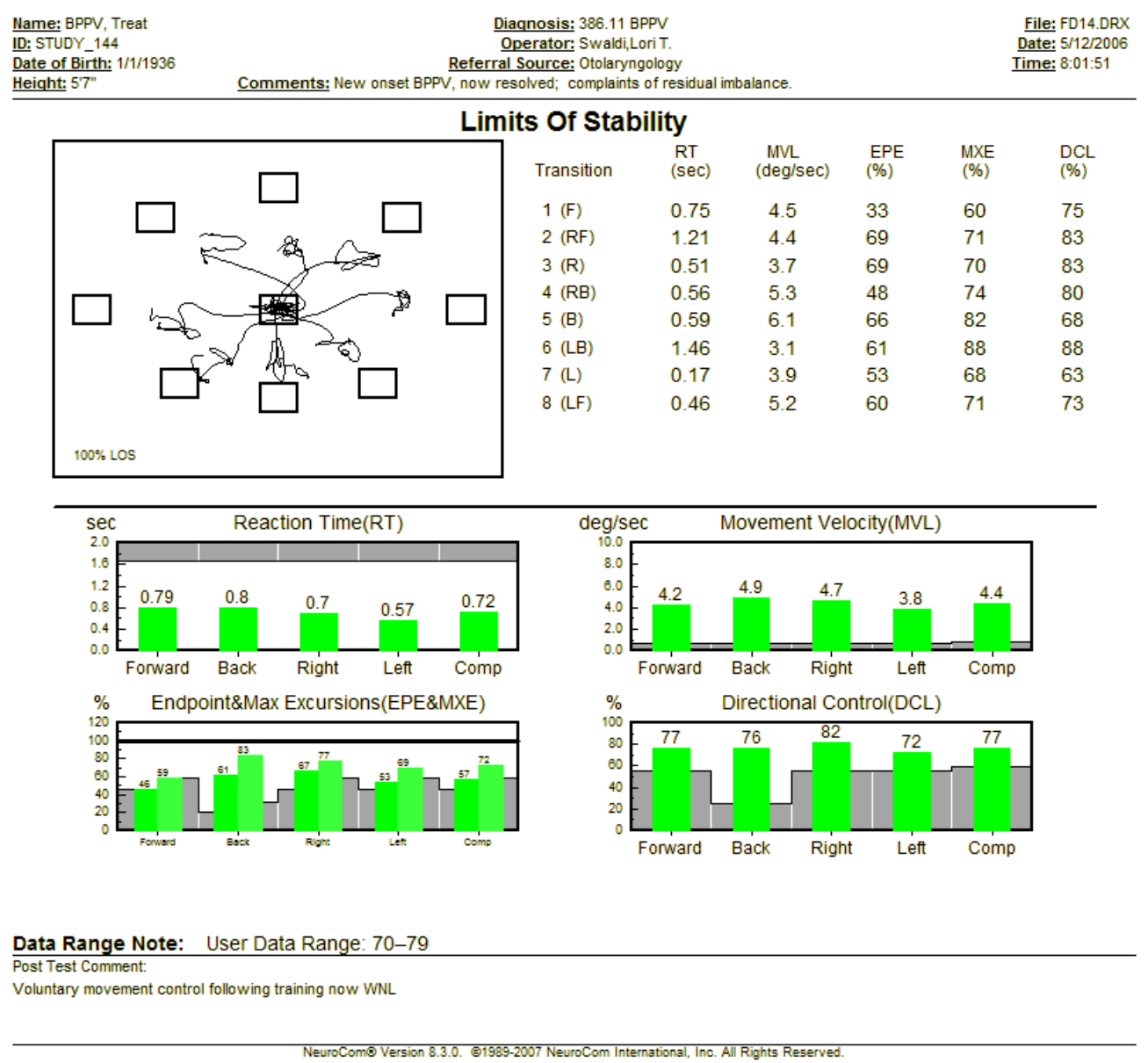

Figura 11. Relatório produzido pelo Balance Master indicando valores normais no Teste de Limites de Estabilidade para um idoso com 79 anos

\subsection{Avaliação da Força Muscular Voluntária}

A avaliação da força muscular voluntária foi realizada através de um dinamômetro manual - Baseline eletronic Smedly hand dynamometer. Para a realização dos testes o voluntário deveria permanecer com o ombro aduzido em posição neutra, cotovelo fletido a 90‥ Realizava um aperto de mão o mais forte possível. Três tentativas foram registradas em ambos os membros. Os valores obtidos foram ajustados de acordo com a idade e sexo. Foi considerado para análise o maior valor obtido (Anexo H) (Klidjian et al., 1980). 


\subsection{ORIGEM DOS RECURSOS FINANCEIROS}

Este estudo foi aprovado pelo Comitê de Ética da CAPEPesq n.149.925 em 21/11/2012. Faz parte do projeto temático "Biometeorologia humana: análise dos efeitos de variáveis ambientais (meteorológicas, conforto térmico e poluição atmosférica) e de mudanças climáticas na população geriátrica da cidade de São Paulo" financiado pela FAPESP- Fundação de Amparo à Pesquisa do Estado de São Paulo, processo no 2010/10189-5. E do projeto do Grupo Temático: Envelhecimento do Instituto Nacional de Análise Integrada do Risco Ambiental INAIRA, financiado pelo $\mathrm{CNPq}$ - Conselho Nacional de Desenvolvimento Cientifico e Tecnológico, processo no $573813 / 2008-6$ e pela FAPESP $n^{\circ}$ 200857717-6.

\subsection{ANÁLISE DOS DADOS}

A amostra foi caracterizada através da análise estatística descritiva, com resultados expressos em porcentagem e frequências, médias e desvios padrão. Foram realizados os seguintes testes estatísticos:

A Correlação de Spearman: para, a partir da analise de correlação, determinar o grau de associação entre duas variáveis.

Teste de Wilcoxon: para determinar tanto a magnitude quanto a direção dos dados nas situações com e sem ruído.

O nível de significância aceito para este estudo foi inferior a 0,05 (5\%).

A execução dos cálculos foi feita através do Software SPSS 18.0 for Windows ${ }^{\circledR}$ (Statistical Package for Social Science, version 18.0). 


\section{RESULTADOS}

\subsection{Análise descritiva de caracterização da amostra estudada}

Inicialmente foram selecionados 23 pacientes, que respondiam aos critérios de inclusão desenhados no estudo. Destes 3 foram excluídos, sendo um por não preencher o critério de equilíbrio mínimo para realizar os testes na plataforma de pressão (pontuação maior ou igual a 7) e 2 por apresentarem pontuação do GDS superior ao pré-estabelecido (maior que 5 pontos), sugerindo presença de sintomas depressivos.

O perfil clínico e sociodemográfico dos 20 idosos selecionados (10 mulheres) encontra-se melhor detalhado na Tabela 1. Salienta-se que nas mulheres a média de idade foi de $69,7 \pm(4,85)$ anos e nos homens $74,7 \pm(3,46)$ anos $(p=0,172)$, enquanto que a escolaridade para as mulheres foi de 8,5 $\pm(4,27)$ anos e para as os homens de $7,0 \pm(4,37)(p=0,160)$. 
Tabela 1 - Características sociodemográficas da amostra estudada ( $\mathrm{N}=20)$

\begin{tabular}{|c|c|c|}
\hline Descritores & Média (DP) & $\mathrm{N}(\%)$ \\
\hline Escolaridade (anos) & $7,75(4,28)$ & \\
\hline Idade (anos) & $72,20(4,84)$ & \\
\hline IMC & $25,27(3,54)$ & \\
\hline MEEM (pontos) & $28,35(1,23)$ & \\
\hline GDS (pontos) & $1,20(1,28)$ & \\
\hline SPPB (pontos) & $11,40(0,5)$ & \\
\hline \multicolumn{3}{|l|}{ Sexo } \\
\hline Feminino & & (10)50 \\
\hline Masculino & & (10)50 \\
\hline \multicolumn{3}{|l|}{ Estado civil } \\
\hline Casado & & (10)50 \\
\hline Viúvo & & $(4) 20$ \\
\hline Solteiro & & (2) 10 \\
\hline Divorciado & & (4)20 \\
\hline \multicolumn{3}{|l|}{ Situação } \\
\hline \multicolumn{3}{|l|}{ previdenciária } \\
\hline Trabalhador & & (3) 15 \\
\hline Aposentado & & (17)85 \\
\hline \multicolumn{3}{|l|}{ Tabagismo } \\
\hline Não & & (18)90 \\
\hline \multicolumn{3}{|l|}{ Pratica de atividade } \\
\hline física & & (11)55 \\
\hline \multicolumn{3}{|l|}{ Lateralidade manual } \\
\hline Destro & & (20)100 \\
\hline
\end{tabular}

IMC - Índice de Massa Corporal MEEM - Mini Exame do Estado Mental GDS - Geriatric Depression Scale SPPB - Short Physical Performance Battery 


\subsection{Avaliações cognitivas pré protocolo}

Os 20 pacientes selecionados realizaram a série de testes cognitivos por duas vezes, uma vez para aprendizado e logo em sequência, pela segunda vez. Os resultados das séries estão descritos na Tabela 2.

Tabela 2 - Comparação dos resultados dos testes T1 e T2 da função cognitiva $(\mathrm{N}=20)$

\begin{tabular}{lccc}
\hline Testes & T1 (N=)20 & T2 (N=)20 & p(valor) \\
& Média (DP) & Média (DP) & \\
\hline Trail Making A (s) & $85,4(33,6)$ & $72,8(21,0)$ & $\mathbf{0 , 0 1 9}$ \\
Trail Making B (s) & $168,0(68,6)$ & $160,6(63,9)$ & 0,550 \\
Spatial Recognition & $2,95(1,23)$ & $3,15(0,93)$ & 0,450 \\
Go/No Go $(\mathrm{ms})^{* *}$ & $583,2(115,0)$ & $555,9(84,8)$ & 0,601 \\
Go/No Go & $0,3(0,571)$ & $0,4(0,598)$ & 0,317 \\
Memory Span & $3,70(0,80)$ & $4,10(1,15)$ & 0,163 \\
Reverse Memory Span & $3,15(0,99)$ & $3,15(1,23)$ & 0,869 \\
Pattern Recognition & $8,45(1,99)$ & $8,30(1,92)$ & 0,700 \\
\hline
\end{tabular}

* (s) segundo

** (ms) milissegundos

Observamos melhora do desempenho significante somente no teste Trail Making $A$, indicando efeito de aprendizado na repetição do teste. Os demais testes não evidenciaram alteração na performance.

Este resultado observado no Teste Trail Making A não se correlacionou com idade $(p=0,337)$ e escolaridade $(p=0,362)$ segundo o teste de Spearman, mesmo quando foram comparados os percentuais de aprendizado (T2-T1/T1). O teste t-Student também não mostrou diferença significativa entre o percentual de aprendizado de homens e mulheres $(p=0,465)$. 


\subsection{Comparação entre os resultados dos testes realizados em ambiente controlado e os testes realizados com ruído}

As avaliações das funções cognitivas foram computadorizas e realizadas em dois momentos. Em ambiente controlado e com ruído semelhante à poluição sonora urbana. Os resultados mostraram diferença estatisticamente significante, demonstrando melhora da performance nos testes de atenção.

O Trail Making $A$ apresentou média de $83,4(27,1) \mathrm{ms}$ no ambiente controlado e um tempo menor no ambiente com ruído 75,1(28,5)ms. O valor de $p$ apresentado na comparação foi 0,028.

O Trail Making $B$ apresentou média de $169,5(66,9) \mathrm{ms}$ no ambiente controlado e um tempo menor no ambiente com ruído 120,6(45,7)ms. O valor de p apresentado na comparação foi 0,008.

Os demais testes cognitivos não apresentaram diferença estatisticamente significante na comparação das duas avaliações, demonstrando não ter havido alteração diante da exposição ao ruído nos teses Go/No-Go; Pattern Recognition; Spatial Recognition; Digit Span; Reverse Digit Span; Memory Span e Reverse Memory Span. 
Tabela 3 - Comparação dos resultados dos testes de função cognitiva em ambiente controlado e com ruído $(\mathrm{N}=20)$

\begin{tabular}{lccc}
\hline Testes & $\begin{array}{c}\text { Sem ruído (N=)20 Com ruído (N=)20 } \\
\text { Média (DP) }\end{array}$ & p(valor) \\
& Média(DP) & \\
\hline $\begin{array}{l}\text { Go/No-Go (ms) } \\
\text { Pattern }\end{array}$ & $9(2,03)$ & $8,45(1,85)$ & 0,723 \\
Recognition & $2,80(1,47)$ & $2,80(1,20)$ & 0,206 \\
Spatial Recognition & $5,35(1,09)$ & $5,15(1,31)$ & 0,711 \\
Digit Span & $3,80(1,06)$ & $3,65(0,81)$ & 0,206 \\
Reverse Digit Span & $4,0(1,17)$ & $4,0(1,12)$ & 0,5 \\
Memory Span & $4,0(1,81)$ & $3,2(1,32)$ & 1 \\
Reverse Memory & $83,4(27,1)$ & $75,1(28,5)$ & 0,063 \\
Span & $169,5(66,9)$ & $120,6(45,7)$ & $\mathbf{0 , 0 2 8}$ \\
Trial Making A (s) & & & $\mathbf{0 , 0 0 8}$ \\
Trial Making B (s) & & & \\
\hline ms) milissegundo & & & \\
\hline
\end{tabular}

(ms) milissegundo

(s) segundo

As avaliações do equilíbrio foram realizadas com auxílio de uma plataforma de pressão. O teste CTSIB não mostrou diferença estatística significativa nas oscilações corporais nas diferentes situações de solo e aferências visuais: solo estável com olhos abertos, solo estável com olhos fechados, solo instável e olhos abertos, solo instável e olhos fechados. 
Tabela 4 - Comparação dos resultados do teste de equilíbrio, na plataforma de pressão, CTSIB em ambiente controlado e com ruído, nas diferentes situações sensoriais. $(\mathrm{N}=20)$

\begin{tabular}{lccc}
\hline Testes & $\begin{array}{c}\text { Sem ruído (N=)20 Com ruído (N=)20 } \\
\text { Média (DP) }\end{array}$ & $\begin{array}{c}\text { p(valor) } \\
\text { Média(DP) }\end{array}$ \\
\hline Estável OA & $0,26(0,07)$ & $0,65(0,20)$ & 0,808 \\
Estável OF & $0,41(0,15)$ & $2,34(0,75)$ & 0,206 \\
Instável OA & $0,69(0,23)$ & $2,80(1,20)$ & 0,340 \\
Instável OF & $2,09(0,60)$ & $2,34(0,75)$ & 0,289 \\
Instável & $0,89(0,21)$ & $0,91(0,23)$ & 0,711 \\
\hline
\end{tabular}

OA - olhos abertos na realização do teste

OF - olhos fechados na realização do teste

O LoS, também realizado na plataforma de força, se propôs a avaliar diferentes parâmetros.

O tempo de reação foi verificado no sentido dos quatro pontos cardiais e uma variável denominada composta que engloba uma média das aferições. Não foi possível verificar diferença estatística entre os valores de tempo de reação apresentados nas duas avaliações realizadas, com ruído e em ambiente controlado: tempo de reação anterior $(p=0,962)$; tempo de reação posterior $(p=, 679)$; tempo de reação a direita $(p=0,702)$; tempo de reação a esquerda $(p=0,616)$ e na variável composta.

Tabela 5 - Comparação dos resultados da variável Tempo de Reação (TR), realizada para a avaliação do equilíbrio na plataforma de pressão nos testes de em ambiente controlado e com ruído, nas diferentes direções $(\mathrm{N}=20)$

\begin{tabular}{lccc}
\hline Testes & $\begin{array}{c}\text { Sem ruído (N=)20 } \\
\text { Média (DP) }\end{array}$ & $\begin{array}{c}\text { Com ruído (N=)20 } \\
\text { Média(DP) }\end{array}$ & p(valor) \\
\hline TR anterior & $1,06(0,26)$ & $1,04(0,27)$ & 0,962 \\
TR posterior & $0,87(0,35)$ & $0,81(0,23)$ & 0,679 \\
TR à direita & $1,02(0,37)$ & $0,93(0,28)$ & 0,702 \\
TR à esquerda & $0,89(0,37)$ & $0,92(0,28)$ & 0,490 \\
Composta & $0,96(0,21)$ & $0,94(0,17)$ & 0,616 \\
\hline
\end{tabular}


A velocidade do movimento foi medida em graus. Observamos uma diferença estatística significante na velocidade de movimento à direita $(p=0,028)$, indicando uma maior velocidade quando solicitado o deslocamento para o lado direito no teste em que o ruído estava presente. Porém não foi observada alteração significante nas variáveis Composta $(p=, 052)$; Velocidade de Movimento Anterior ( $p=0,542)$; Velocidade de Movimento Posterior $(p=0,764)$ e Velocidade de Movimento a Esquerda $(p=0,846)$.

Tabela 6 - Comparação dos resultados da variável Velocidade do Movimento (VM), realizada para a avaliação do equilíbrio na plataforma de pressão nos testes de em ambiente controlado e com ruído, nas diferentes direções. $(\mathrm{N}=20)$

\begin{tabular}{lccc}
\hline Testes & $\begin{array}{c}\text { Sem ruído (N=)20 } \\
\text { Média (DP) }\end{array}$ & Média(DP) & ruído (N=)20 \\
& p(valor) \\
\hline VM anterior $(\% / \mathrm{s})$ & $2,89(0,08)$ & $2,90(1,11)$ & 0,542 \\
VM posterior $(\% / \mathrm{s})$ & $2,33(0,88)$ & $2,51(1,63)$ & 0,764 \\
VM a direita $(\% / \mathrm{s})$ & $4,24(1,96)$ & $4,86(2,17)$ & $\mathbf{0 , 0 2 8}$ \\
VM a esquerda $(\% / \mathrm{s})$ & $4,65(1,74)$ & $4,75(2,26)$ & 0,846 \\
Composto & $3,46(1,18)$ & $3,76(1,49)$ & 0,052 \\
\hline
\end{tabular}

* $(\% / s)$ - graus por segundo

A variável Ponto de Excursão Final não apresentou diferença estatística entre os dois momentos de avaliação nas seguintes direções: anterior $(p=0,219)$; posterior $(p=0,601)$; a direita $(p=0,325)$; a esquerda $(p=0,401)$ e composta $(p=0,647)$. 
Tabela 7 - Comparação dos resultados da variável Ponto Final de Excursão (PFE), realizada para a avaliação do equilíbrio na plataforma de pressão nos testes de em ambiente controlado e com ruído, nas diferentes direções $(\mathrm{N}=20)$

\begin{tabular}{lccc}
\hline Testes & $\begin{array}{c}\text { Sem ruído (N=)20 } \\
\text { \% }\end{array}$ & $\begin{array}{c}\text { Com ruído (N=)20 } \\
\text { \%(valor) }\end{array}$ & \\
\hline PFE anterior & 2,89 & 2,90 & 0,219 \\
PFE posterior & 2,33 & 2,51 & 0,601 \\
PFE à direita & 4,24 & 4,86 & 0,401 \\
PFE à esquerda & 4,65 & 4,75 & 0,325 \\
Composto & 3,46 & 3,76 & 0,647 \\
\hline
\end{tabular}

Assim como a variável Velocidade de Movimento, a Excursão Máxima (EM) demonstrou diferença estatística somente em relação a direção direita $(p=0,011)$. As demais direções, anterior $(p=0,198)$; posterior $(p=0,444)$; esquerda $(p=0,737)$ e a variável Composta $(p=0,090)$ não mostraram diferença importante entre a avaliação com ruído e a avaliação em ambiente controlado.

Tabela 8 - Comparação dos resultados da variável Excursão Máxima (EM), realizada para a avaliação do equilíbrio na plataforma de pressão nos testes de em ambiente controlado e com ruído, nas diferentes direções $(\mathrm{N}=20)$

\begin{tabular}{lccc}
\hline Testes & Sem ruído (N=)20 & Com ruído (N=)20 & p(valor) \\
& $\%$ & $\%$ & \\
\hline EM anterior & 72,4 & 26,1 & 0,198 \\
EM posterior & 54,7 & 59,3 & 0,444 \\
EM a direita & 92,0 & 101,4 & $\mathbf{0 , 0 1 1}$ \\
EM a esquerda & 95,9 & 95,4 & 0,737 \\
Composto & 79,7 & 81,3 & 0,090 \\
\hline
\end{tabular}

A variável Controle de Direção não apresentou diferença estatística na comparação entre os resultados obtidos nos dois momentos de avaliação (em ambiente controlado e com ruído) nas seguintes direções: anterior ( $p=0,112)$; 
posterior $(p=0,811)$; direita $(p=0,984)$; esquerda $(p=0,183)$ e a variável Composta $(p=0,570)$.

Tabela 9 - Comparação dos resultados da variável Controle de Direção (CD), realizada para a avaliação do equilíbrio na plataforma de pressão nos testes de em ambiente controlado e com ruído, nas diferentes direções $(\mathrm{N}=20)$

\begin{tabular}{lccc}
\hline Testes & $\begin{array}{c}\text { Sem ruído }(\mathbf{N}=) 20 \\
\text { \% }\end{array}$ & Com ruído (N=)20 & p(valor) \\
\hline CD anterior & 67,1 & 73,1 & \\
CD posterior & 54,5 & 56,4 & 0,112 \\
CD à direita & 70,7 & 71,5 & 0,811 \\
CD à esquerda & 70,7 & 72,3 & 0,984 \\
Composto & 66,6 & 69,1 & 0,183 \\
\hline
\end{tabular}

O teste de preensão manual não apontou diferença estatística significante nos dois momentos de realização do teste, com e sem ruído $(p=0,823)$.

Tabela 10 - Comparação dos resultados do teste de preensão manual realizado em ambiente controlado e com ruído $(\mathrm{N}=20)$

\begin{tabular}{lccc}
\hline Testes & $\begin{array}{c}\text { Sem ruído (N=)20 } \\
\text { Média (DP) }\end{array}$ & $\begin{array}{c}\text { Com ruído (N=)20 } \\
\text { Média(DP) }\end{array}$ & (valor) \\
\hline $\begin{array}{l}\text { Teste de preensão } \\
\text { manual }(\mathrm{kg})\end{array}$ & $33,0(14,1)$ & $32,6(13,0)$ & 0,823 \\
\hline
\end{tabular}

(kg) - quilograma

\subsection{Avaliação do desconforto}

Todos os voluntários do estudo residiam na cidade de São Paulo há pelo menos 30 anos, a maioria (55\%) em casas e $90 \%$ relatou permanecer fora de casa pelo menos 4 horas por dia, indicando uma vida ativa e com isso a frequente exposição a poluição sonora urbana. Quando interrogado sobre a frequência semanal com que se expõem a ruído semelhante ao utilizado nos 
testes, a maioria (85\%) afirmou que a exposição era diária, 10\% mais de uma vez por semana e 5\% menos de uma vez por semana. Os idosos voluntários em sua maioria, perceberam o ruído como um incomodo moderado e não notaram dificuldade na realização dos testes de equilíbrio, força ou cognição devido a presença do ruído. A percepção do desconforto relatada pelo voluntário na realização dos testes foi descrita na Tabela 11.

Tabela 11 - Impressão de desconforto relatada pelos idosos na realização dos testes com ruído $(\mathrm{N}=20)$

\begin{tabular}{lcc}
\hline Descritores & N & $\%$ \\
\hline Percepção do ruído no teste & 2 & 10 \\
$\quad$ Ausente & 2 & 10 \\
Mínimo & 4 & 20 \\
Leve & 8 & 40 \\
$\quad$ Moderado & 4 & 20 \\
$\quad$ Intenso & & \\
Dificuldade no teste cognitivo & 2 & 10 \\
$\quad$ Sim & 18 & 90 \\
$\quad$ Não & & \\
Dificuldade no teste de equilíbrio & 0 & 0 \\
$\quad$ Sim & 20 & 100 \\
Não & & \\
Dificuldade no teste de força & 0 & 0 \\
Sim & 20 & 100 \\
$\quad$ Não &
\end{tabular}




\section{DISCUSSÃO}

Nossos dados demonstraram uma melhora, significante, nos resultados do Teste Trail Making, na comparação entre as avaliações iniciais em ambiente com ruído controlado. Estudos recentes mostraram que a melhora do desempenho ocasionada pelo efeito da prática pode permanecer de 1 a 6 semanas, deixando de ser significante de 1 a 7 anos após a avaliação inicial (Salthouse, et al., 2004; Bates et al 2005).

Poucos estudos, porém avaliam o efeito de aprendizado, em testes cognitivos computadorizados. Raymond et al. (2006) aplicaram uma bateria de testes computadorizados (MicroCog) e encontraram efeitos significativos de aprendizado ao realizá-la por duas vezes com um intervalo de 2 semanas. A melhora do desempenho foi atribuída ao aumento da confiança com o uso do computador.

Estudo realizado por Beglinger et al. (2004) com adultos saudáveis, fazendo uso de drogas para melhorar a função cognitiva, mostrou melhora da pontuação nos testes computadorizados mesmo nos indivíduos que não sofreram intervenção medicamentosa ao longo das 6 repetições realizadas, mostrando um elevado aprendizado no Teste Trail Making A, principalmente nas terceira e quarta repetições. O mesmo ganho de performance não pode ser observado nos resultados do Teste Trail Making B, assim como em nosso estudo.

Acreditamos que no nosso estudo, o fato dos testes serem computadorizados possa ter aumentado o grau de ansiedade e receio de inabilidade para conclusão dos testes, independente das características socioeconômicas. O fato de a população avaliada ser exclusivamente idosa também colabora para o aumento da ansiedade visto que historicamente o uso frequente de computadores é menor nesta faixa etária (Cutler et al., 2003) e no nosso o uso do computador foi relatado em uma pequena parcela da amostra (20\%). Importante ressaltar que o primeiro teste a ser realizado foi o Trail Making $A$. Fato esse que pode ter comprometido o rendimento da primeira avaliação, levando a uma diferença significante na comparação das duas performances. 
Lezak et al. (2012) afirmam que após a realização do primeiro teste, as estratégias desenvolvidas para vencer a tarefa podem facilitar o desempenho das demais avaliações, já na primeira aplicação, reduzindo o percentual de evolução, na comparação dos resultados das duas avaliações. Dado que colabora para a ausência de efeito de aprendizado significante nos demais testes realizados, mostrando que após ser introduzido o manuseio do computador, os voluntários tiveram maior facilidade para desempenhar os testes.

Alguns autores afirmam que na comparação do efeito da aprendizagem entre jovens e idosos o avançar da idade faz com que o desempenho nas avaliações se torne semelhante, porém os fatores que levam a população idosa a apresentar menor efeito de aprendizado ainda não são claros (Temkin et al., 1999). A menor capacidade de memorização e codificação de informações relevantes no teste inicial pode ser uma causa para tal achado.

Independente do tempo de intervalo entre as avaliações, e até mesmo a idade dos voluntários, os fatores individuais, como motivação no momento da avaliação inicial, condições clínicas satisfatórias, coeficiente de inteligência elevado e a alta escolaridade podem favorecer o efeito de aprendizagem (Rapport et al., 1997; Salthouse, 2011).

Estudo realizado com os testes Trail Making $A$ e $B$ em suas versões tradicionais mostrou não haver diferença entre indivíduos de diferentes faixas etárias (Salthouse et al., 2000). Acreditamos que os testes por nós empregados, seja pela baixa complexidade, seja pelo fornecimento das instruções adequadas, facilitaram o desempenho independente de fatores como idade e escolaridade.

Duff et al. (2012) encontraram, em 268 adultos, ausência de associação entre dados sociodemográficos (sexo, escolaridade e idade) e a intensidade de efeito de aprendizado nos testes cognitivos tradicionais, o que concorda com nossos resultados.

Grande parte dos estudos destinados a verificar o efeito da aprendizagem foi realizada em adultos jovens, com média de idade em torno de 50 anos. Mesmo quando destinada a avaliar o impacto da idade neste fenômeno.

Os estudos que avaliam a interferência produzida pela presença de ruídos durante a realização de tarefas relatam que os resultados dependem de vários 
fatores, como a sua natureza, a intensidade e as tarefas desenvolvidas. Os ruídos previsíveis e constantes são menos impactantes que os imprevisíveis e os que apresentam variação na intensidade, considerados intermitentes (Gullian, 1967).

Além das características do evento estressor, a avaliação que o indivíduo faz a respeito de sua capacidade de enfrentamento influencia a reação ao estresse tanto em situações agudas como crônicas (Monat et al., 2007). Deste modo, a sensibilidade individual ao ruído também deve ser encarada como um fator que interfere nas respostas diante da presença do mesmo (Zimmer e Ellermeier, 1999). O incomodo ou desconforto provocado pelo ruído é resultado de quanto este fator interfere na realização de sua atividade, tornando o estressor mais importante que a própria atividade. Quanto maior a sensibilidade ao ruído, mais intensas seriam as reações produzidas por este (Job, 1999; Miedema e Vos, 2003).

Em nosso estudo, embora não tenhamos avaliado a sensibilidade ao ruído diretamente, questionamos sobre o desconforto produzido, perguntando aos voluntários o quanto se sentiram perturbados por ele, logo após a realização desta etapa do protocolo. Embora $60 \%$ tenha relatado que o ruído de fundo causava um desconforto moderado a intenso, somente $10 \%$ relatou ter percebido maior dificuldade na realização dos testes cognitivos quando na sua presença. Para as demais tarefas não houve relato de desconforto. Vale lembrar que $85 \%$ da amostra relatava exposição prévia semelhante diariamente, fato esse que pode ter facilitado a ambientação para sua realização. Acreditamos que os idosos participantes do estudo possuam baixa sensibilidade ao ruído, mediante ao pequeno percentual de desconforto relatado.

A avaliação psicológica dos indivíduos também pode ser um fator determinante para o desempenho diante do ruído. Pessoas com personalidade mais estável, com comportamento extrovertido e com uma menor sensibilidade subjetiva ao ruído, podem apresentar melhores resultados em tarefas de desempenho mental, em comparação com as pessoas com a personalidade oposta (Cassidy e MacDonald, 2007). Dessa forma podemos perceber uma grande variedade de características pessoais levando a diferentes desempenhos. 
Outro fator importante é que o efeito do ruído pode variar de acordo com a complexidade da tarefa. Alguns estudos apontaram relação entre a complexidade da tarefa com o incomodo e desempenho obtido (Koelega et al., 1986; Kjellberg e Sköldström, 1991) outros estudos não encontraram esta relação (Belojevic et al. 2001; Ma e Yano, 2004). Uma possível causa para esta divergência de achados pode ser explicada pela maior demanda de esforço para a realização de atividades complexas, mas também pela criação de estratégias de enfrentamento, aumentando a atenção.

Nossos dados mostraram que na presença do ruído, os idosos avaliados apresentaram melhora significativa no desempenho observada somente nas tarefas cognitivas que avaliavam a atenção (Trail Making $A$ e $B$ ). Segundo Tafalla et al. (1988), o estresse, que pode ser produzido pela presença do ruído, aumenta o funcionamento cardiovascular e neuroendócrino durante a realização das tarefas cognitivas, alterando o seu desempenho.

Esse estresse promove um processo reativo que aciona um conjunto de respostas orgânicas e/ou comportamentais relacionadas a mudanças fisiológicas padrão, incluindo a hiperfunção da glândula supra-renal ou adrenal. $O$ estabelecimento do estresse se dá com o aumento da produção de glicocorticóides, mais precisamente de cortisol.

Selye (1946) denominou de Síndrome Geral da Adaptação (SGA) à soma de todas as reações sistêmicas não específicas que surgem em respostas a uma longa e continuada exposição ao estressor. Dividiu a SGA em três fases: alarme, na qual são experimentadas sensações característica da alteração do equilíbrio interno do organismo; resistência, quando o organismo tenta adaptarse ao estressor; descompensação ou exaustão, que advém do esgotamento dos recursos adaptativos, levando o indivíduo à exaustão.

Devido ao tempo de exposição ao agente estressor neste estudo, os voluntários experimentaram apenas a fase de alarme, que é curta (durando alguns minutos ou horas), e se relaciona com a ação do Sistema Nervoso Autônomo (SNA) e liberação de catecolaminas, adrenalina e noradrenalina, pela medula da supra-renal. No primeiro momento da SGA, a resposta orgânica é neural, pela ativação do SNA, que é seguida de uma resposta humoral, devido à liberação de catecolaminas desencadeada pelo próprio SNA. 
$\mathrm{Na}$ fase de alarme é desencadeada uma série de reações fisiológicas para a sobrevivência, dentre elas o aumento da pressão arterial, tensão muscular, frequência respiratória, mobilização de energia, elevação no nível de atenção e velocidade na articulação de pensamentos, além do aumento na motivação e disponibilidade para envolver-se em novos projetos (Lipp, 2003), o que colabora para justificar nossos resultados positivos, produzidos diante do ruído, nos testes de atenção.

Broadbent (1978) explica que o ruído pode afetar o desempenho, prejudicando o processamento de informações ou, alternativamente, induzindo mudanças na resposta estratégica. Mesmo aumentando os níveis de alerta geral, ativação e seletividade de atenção, como já mencionamos, pode causar a redução da precisão do desempenho, principalmente na memória de trabalho de curto prazo. Isso ocorre porque o ruído promove uma excitação no indivíduo, que responde a este estímulo focando sua atenção na tarefa, mas, ao mesmo tempo em que, direciona a atenção à tarefa e tenta ignorar estímulos irrelevantes, como o próprio ruído, ele pode acabar ignorando componentes relevantes da tarefa e deste modo ter o seu desempenho prejudicado.

No modelo proposto por Poulton (1979) este prejuízo para estímulos relevantes é chamado de mascaramento e segundo o autor, ao expor o individuo ao ruído, inicialmente a excitação se sobrepõem ao mascaramento, o que confere melhores performances com o ruído nas primeiras atividades desenvolvidas. A partir desta perspectiva, os ganhos de desempenho no ruído no início da tarefa podem ocorrer porque o aumento da excitação compensa os efeitos deletérios do mascaramento. No entanto, com o tempo na tarefa, excitação diminui, e efeitos de mascaramento passam a ser mais expressivos. Essa melhora no desempenho inicial pode ter sido também um dos fatores causais para os resultados observados nos Trail Making $A$ e $B$ em nosso estudo.

Comparando o envelhecimento bem sucedido com 0 patológico, observamos que no último ocorre uma hiperatividade do eixo HipotálamoHipófise-Adrenal, caracterizada pelo aumento dos níveis de cortisol, fenômeno comumente observado durante condições de estresse (O'Brien et al., 1994).

Este aumento do cortisol promove prejuízos cognitivos. Como observamos em um estudo realizado com homens e mulheres entre 45 e 50 anos, no qual 
foram administrados testes padronizados para avaliar memória verbal imediata e tardia, fluência verbal e velocidade de processamento, mostraram que altos níveis de cortisol no final da manhã foram associados com pior memória e fluência verbal (Geoffroy et al., 2012).

$\mathrm{Na}$ literatura encontramos estudos com resultados divergentes em relação ao desempenho de tarefas cognitivas na presença do ruído. Uma meta-análise com mais de duzentos estudos, que se propunham a avaliar a interferência do ruído no desempenho de atividades, mostrou que em sua maioria, as tarefas avaliadas eram cognitivas. Classificaram as tarefas cognitivas em atividades que avaliam a precisão e a velocidade das respostas. Os dados apontaram para um pequeno a médio efeito negativo sobre a precisão e um efeito positivo leve sobre a velocidade de resposta nas tarefas avaliadas. (Salzama e Hancock, 2011).

Nossos dados nos Trail Making $A$ e $B$ concordam com os achados da metaanálise por terem melhorares resultados com o ruído, mas não mostraram modificação nos demais testes. Estes achados podem ser indicativos de que a sensibilidade ao ruído, de modo a interferir nas tarefas cognitivas, diminua com o envelhecimento.

Ainda nesta meta-análise, Szalma e Hancock (2011) observaram que o método mais utilizado, para avaliar o desempenho dos indivíduos diante da presença de ruído, foi através da aplicação de testes cognitivos. Dos 242 artigos selecionados no estudo, apenas 11 avaliavam tarefas motoras, predominantemente de coordenação e nenhuma de equilíbrio.

Diferentemente dos demais estudos, que avaliam o equilíbrio através da vibração produzida por ruídos contínuos sob os pés, produzindo um distrator proprioceptivo (Priplata et al., 2003; Wu et al 2007; Magalhães e Kohn, 2011; Melzer et al., 2011; Thompson et al., 2011) nosso estudo verificou a interferência do ruído na manutenção do equilíbrio estático e nos deslocamentos do centro de massa dentro da base de apoio. Diante desta exposição, observamos a presença da melhora do desempenho através da variável Excursão Máxima à direita e Velocidade do Movimento a direita. Vale lembrar que todos os voluntários eram destros. A maior distância percorrida, apresentada pela Excursão Máxima e o menor tempo necessário para alcançar o alvo, observado na Velocidade do Movimento, ambas variáveis obtidas no teste de Limites de 
Estabilidade, demonstraram uma maior agilidade para o lado dominante na presença do ruído. Contudo, como não foi possível observar o mesmo ganho nas variáveis Controle de Direção e Ponto Final de Excursão, não ocorreu alteração do desempenho nos testes de equilíbrio estático e limites de estabilidade.

Não encontramos estudos na literatura que correlacionassem a força muscular com a presença de ruídos. Em nosso estudo os testes de preensão palmar não mostraram alteração do desempenho na presença do ruído.

Como tradicionalmente credita-se ao ruído sonoro a possibilidade de ser distrator que frequentemente prejudica o desempenho cognitivo e/ou motor, o que o inclui no capítulo dos agressores do cotidiano na forma de uma poluição sonora. Nossos dados demonstram que mesmo utilizando um ruído sabidamente inadequado mediante os critérios da OMS, não foram observados piora do desempenho nos testes motores e cognitivos. 


\section{CONCLUSÕES}

Os ruídos sonoros alteram a função cognitiva dos idosos da comunidade, melhorando o desempenho em testes de atenção.

Não observamos alteração no desempenho das demais funções cognitivas avaliadas: memória imediata, memória de trabalho, habilidades visuo-espaciais e tempo de reação.

O equilíbrio estático, os limites de estabilidade e a força de preensão manual dos idosos da comunidade não foram modificados pela emissão de ruídos sonoros. 


\section{ANEXO A Termo de Consentimento Livre e Esclarecido}

HOSPITAL DAS CLÍNICAS DA FACULDADE DE MEDICINA DA UNIVERSIDADE DE SÃO PAULO
TERMO DE CONSENTIMENTO LIVRE E ESCLARECIDO

DADOS DE IDENTIFICAÇÃO DO SUJEITO DA PESQUISA E RESPONSÁVEL LEGAL

1.NOME:

DOCUMENTO DE IDENTIDADE №: SEXO: ( ) M ( ) F

DATA DE NASCIMENTO:

ENDEREÇO:

BAIRRO: CIDADE:

CEP: TELEFONE:

\section{DADOS SOBRE A PESQUISA}

\section{TÍTULO DO PROTOCOLO DE PESQUISA:}

"Impacto da poluição sonora urbana no desempenho de indivíduos idosos saudáveis - estudo experimental"

\section{PESQUISADOR:}

NOME: Wilson Jacob Filho

CARGO/FUNÇÃO: Professor Titular da Disciplina de Geriatria da Faculdade de Medicina da USP / Diretor do Serviço de Geriatria do Hospital das Clínicas da FMUSP

NOME: Rafaela Sanches de Oliveira

CARGO/FUNÇÃO: Fisioterapeuta, matriculada no Curso de Pós-Graduação stricto sensu do Departamento de Clínica Médica da Faculdade de Medicina da Universidade de São Paulo.

INSCRIÇÃO CONSELHO REGIONAL № 77809/F

UNIDADE DO HCFMUSP: Instituto Central

3. AVALIAÇÃO DO RISCO DA PESQUISA:

$$
\begin{array}{cl}
\text { RISCO MÍNIMO } & \text { RISCO MÉDIO } \\
\text { RISCO BAIXO } X & \text { RISCO MAIOR }
\end{array}
$$

4.DURAÇÃO DA PESQUISA: 15 dias

\section{CONVITE}

Convidamos o senhor (a) a participar de um estudo científico sobre a aplicação de testes de memória e atenção, utilizando-se de um programa de computador, avaliação do equilíbrio e força de preensão.

SEU SEGUIMENTO NO AMBULATÓRIO

Caso o senhor (a) esteja em atendimento no ambulatório da geriatria do Hospital das Clínicas, sua participação ou não neste estudo não interferirá no seu seguimento.

COMO SERÁ O ESTUDO?

O estudo consiste em duas sessões de testes. Em um primeiro encontro treinaremos a realização dos testes de memória e atenção realizados com um programa de computador, realizaremos um teste de equilíbrio simples e a aplicação de um questionário clínico, visando 
identificar a presença de doenças, uso de medicações entre outros dados. No segundo encontro, serão realizados os testes de memória e atenção, um teste de equilíbrio realizado em uma plataforma computadorizada e um teste de força avaliado através do aperto de mão. Os testes serão realizados duas vezes, uma com estímulo sonoro, através da apresentação de uma gravação semelhante ao ruído produzido no trânsito de uma grande cidade e outra sem a presença do ruído. A ordem da realização dos testes será decidida por sorteio. O tempo aproximado de cada sessão é de 45 minutos.

\section{RISCOS}

Os testes realizados oferecem risco mínimo. Um dos riscos a se considerar é a perda de equilíbrio durante os testes, que será minimizada, respeitando-se seus limites. Você poderá sentar-se sempre que desejar ou precisar e os pesquisadores permanecerão ao lado para dar suporte.

\section{BENEFÍCIOS}

$\mathrm{O}(\mathrm{A})$ senhor (a) não terá nenhum benefício direto ou imediato com esse estudo.

Acreditamos que os resultados desta pesquisa são relevantes para a população idosa em geral.

Em qualquer etapa do estudo, você terá acesso aos profissionais responsáveis pela pesquisa para esclarecimento de eventuais dúvidas. O principal investigador é o Rafaela Sanches de Oliveira, que pode ser encontrado no endereço Rua Bertioga 160, 54 - Telefone 25894652. Se você tiver alguma consideração ou dúvida sobre a ética da pesquisa, entre em contato com o Comitê de Ética em Pesquisa (CEP) - Rua Ovídio Pires de Campos, 225 - 5o andar - tel: 30696442 ramais 16, 17, 18 ou 20, FAX: 3069-6442 ramal 26 - E-mail: cappesq@hcnet.usp.br

O senhor (a) terá a liberdade de suspender esta autorização a qualquer momento, deixando de participar do estudo, sem prejuízo algum do seu acompanhamento nesse hospital.

As informações obtidas serão analisadas em conjunto com outros pacientes, não sendo divulgada a identificação de nenhum paciente. Você tem o direito de ser mantido atualizado sobre os resultados parciais da pesquisa.

Não há despesas pessoais para o participante em qualquer fase do estudo. Também não há compensação financeira relacionada à sua participação. Os dados coletados serão usados exclusivamente nessa pesquisa.

Acredito ter sido suficientemente informado a respeito das informações que li ou que foram lidas para mim, descrevendo o estudo: "Projeto Piloto: Impacto da poluição sonora urbana no desempenho de indivíduos idosos saudáveis - Estudo Experimental"

Eu discuti com Rafaela Sanches de Oliveira sobre a minha decisão em participar nesse estudo. Ficaram claros para mim quais são os propósitos do estudo, os procedimentos a serem realizados, seus desconfortos e riscos, as garantias de confidencialidade e de esclarecimentos permanentes. Ficou claro também que minha participação é isenta de despesas e que tenho garantia do acesso a tratamento hospitalar quando necessário. Concordo voluntariamente em participar deste estudo e poderei retirar o meu consentimento a qualquer momento, antes ou durante o mesmo, sem penalidades ou prejuízo ou perda de qualquer benefício que eu possa ter adquirido, ou no meu atendimento neste Serviço.

Assinatura do paciente/representante legal Data 11

Assinatura da testemunha

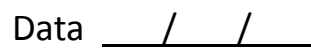




\section{(Somente para o responsável do projeto)}

Declaro que obtive de forma apropriada e voluntária o Consentimento Livre e Esclarecido deste paciente ou representante legal para a participação neste estudo.

Assinatura do responsável pelo estudo

Data $1 / 1$ 


\section{ANEXO B Mini-exame do Estado Mental (MMSE)}

\section{Questões}

Pontos

1. Qual é: Ano? Mês? Dia da semana? Dia do mês? Hora aproximada?

2. Onde estamos: Estado? País? Cidade? Bairro ou hospital? Andar?

3. Nomeie três objetos (carro, vaso, janela) levando 1 segundo para cada. Depois, peça ao paciente que os repita para você. Repita as respostas até o indivíduo aprender as 3 palavras (5 tentativas).

4. 7s seriados: Subtraia 7 de 100. Subtraia 7 desse número, etc. Interrompa após 5 respostas.

5. Peça ao paciente que nomeie os 3 objetos aprendidos em 3.

6. Mostre uma caneta e um relógio. Peça ao paciente que os nomeie conforme você os mostra.

7. Peça ao paciente que repita "nem aqui, nem ali, nem lá".

8 Peça ao paciente que obedeça sua instrução: "Pegue o papel com sua mão 3 direita. Dobre-o ao meio com as duas mãos. Coloque o papel no chão".

9. Peça ao paciente para ler e obedecer o seguinte: "Feche os olhos".

10. Peça ao paciente que escreva uma frase de sua escolha.

11. Peça ao paciente que copie o seguinte desenho:

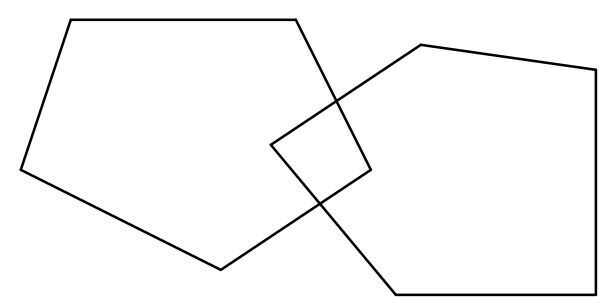

Escore total: (máximo de 30)

Fonte: Folstein et al., 1975; Bertolucci et al., 1994 


\section{ANEXO C Escala de Depressão Geriátrica}

\begin{tabular}{|c|c|}
\hline Você está basicamente satisfeito com sua vida? & $\frac{\text { Não }}{\operatorname{Sim}}$ \\
\hline Você deixou muitos de seus interesses e atividades? & $\begin{array}{l}\text { Não } \\
\text { Sim }\end{array}$ \\
\hline Você sente que sua vida está vazia? & $\begin{array}{l}\text { Não } \\
\text { Sim }\end{array}$ \\
\hline Você se aborrece com frequência? & $\begin{array}{l}\text { Não } \\
\text { Sim }\end{array}$ \\
\hline Você se sente de bom humor a maior parte do tempo? & $\frac{\text { Não }}{\text { Sim }}$ \\
\hline Você tem medo que algum mal vá lhe acontecer? & $\begin{array}{l}\text { Não } \\
\text { Sim }\end{array}$ \\
\hline Você se sente feliz a maior parte do tempo? & $\frac{\overline{\text { Não }}}{\text { Sim }}$ \\
\hline Você sente que sua situação não tem saída? & $\begin{array}{l}\text { Não } \\
\text { Sim }\end{array}$ \\
\hline Você prefere ficar em casa a sair e fazer coisas novas? & $\begin{array}{l}\text { Não } \\
\text { Sim }\end{array}$ \\
\hline Você se sente com mais problemas de memória do que a maioria? & $\begin{array}{l}\text { Não } \\
\text { Sim }\end{array}$ \\
\hline Você acha maravilhoso estar vivo? & $\frac{\overline{\text { Não }}}{\operatorname{Sim}}$ \\
\hline Você se sente um inútil nas atuais circunstâncias? & $\begin{array}{l}\text { Não } \\
\text { Sim }\end{array}$ \\
\hline Você se sente cheio de energia? & $\frac{\overline{\text { Não }}}{\text { Sim }}$ \\
\hline Você acha que sua situação é sem esperanças? & $\begin{array}{l}\text { Não } \\
\text { Sim } \\
\end{array}$ \\
\hline Você sente que a maioria das pessoas está melhor que você? & $\begin{array}{l}\text { Não } \\
\text { Sim }\end{array}$ \\
\hline
\end{tabular}

(SHEIKH, YESAVAGE, 1986)

Pontuação:

Somar um ponto por resposta grifada.

0 a 5 Normal

6 a 10 Depressão Leve

11 ou + Depressão Grave 


\section{ANEXO D Short Physical Performance Battery}

\section{TESTE DE EQUILÍBRIO}

Assinale o quadrado, caso obtenha pontuação zero, assinale o motivo abaixo e passe para o teste seguinte.

$1^{\circ}$ POSIÇÃO: Pés unidos em paralelos

( ) < 10" - 0 ponto. Marque o tempo ms. Assinale o

Assinale o motivo abaixo e siga para o próximo teste (teste de velocidade de marcha).

( ) $\geq 10^{\prime \prime}$ - 1 ponto. Passe para a $2^{\circ}$ posição.

$2^{\circ}$ POSIÇÃO: Hálux encostado na borda medial do calcanhar.

( ) $<10$ " - 0 ponto. Marque o tempo ms. Assinale 0 motivo abaixo e siga para o próximo teste (teste de velocidade de marcha). ( ) >10" - 1 ponto. Passe para a $3^{\circ}$ posição.

$3^{\circ}$ POSIÇÃO: Hálux encostado na borda posterior do calcanhar. ( $)<3$ "-0 ponto. Marque o tempo ms.

Assinale o motivo abaixo e siga para o próximo teste (teste de velocidade de marcha).
() 3" >e $\leq$ 9". 99 -1 ponto
( ) $\geq 10$ " - 2 pontos

\section{SOMA TOTAL DOS PONTOS NAS 3 POSIÇÕES (PONTUAÇÃO EQUILÍBRIO)}

Assinale $\mathbf{x}$ no motivo abaixo, caso a pontuação tenha sido igual a zero:

( ) Tentou, mas não conseguiu;

( ) Participante não é capaz de ficar na posição sem auxílio;

( ) O avaliador sente-se insegurança para deixá-lo na posição;

( ) O participante sente-se inseguro para ficar na posição;

( ) O participante é incapaz de entender a explicação do teste;

( ) Outra questão específica;

( ) O participante recusou.

Comentários 
Caminhar normalmente como se fosse atravessar a rua, repetir 2 vezes o teste. Pode ser utilizado meio auxiliar de marcha, menos cadeira de rodas. Se ele é incapaz de realizar, assinale o motivo e siga para o teste seguinte.

TEMPO DA $1^{\circ}$ VELOCIDADE (ida) ms.

TEMPO DA $2^{\circ}$ VELOCIDADE (volta) ms.

Escolher o melhor tempo para a pontuação, assinalando o quadrado abaixo.

( ) $<4$. 82" 4 pontos

( ) 4.82 " >e $\leq 6.20$ " 3 pontos

() $6.21 \geq e \leq 8.70$ " 2 pontos

( ) $>8.70$ " 1 ponto

() Incapaz 0 ponto.

ASSINALE X NO MOTIVO ABAIXO:

( ) Tentou, mas não conseguiu;

( ) O participante não pode caminhar sem auxílio ou ajuda;

( ) O avaliador sentiu insegurança para realizar o teste;

( ) O participante sentiu-se inseguro para realizar o teste;

( ) O participante não entendeu as instruções do teste;

( ) Outro motivo específico:

( ) O participante recusou.

QUAL A DIFICULDADE NESTE TESTE: ( ) Nenhum ( ) Bengala ( ) Outro

Comentários:

\section{TESTE DE FORÇA DE MEMBROS INFERIORES PONTUAÇÃO FORÇA}

. Primeiro realizar um Pré-teste: levantar-se apenas 1 vez da cadeira:

. Caso NÃO consiga ou utilize as mãos, pare o teste, assinale o motivo abaixo e siga para a pontuação final $S P P B$

. Caso SIM consiga, repita o teste 5 vezes consecutivas o mais rápido possível, com os Membros superiores cruzados sobre peito e marque o tempo:

ms. Caso o participante use os braços ou não consiga completar as 5 repetições ou demore mais que 1 minuto para completar, finalize o teste e pontue zero e assinale o motivo abaixo.

\section{Posição}


Inicial Final ( $)>16 " .7-1$ ponto

() 13 ". $70>$ e $\leq 16$ ". $69-2$ pontos

( ) 11 ". $20>\mathrm{e} \leq 13$ ". $69-3$ pontos

() $<11.19-4$ pontos

( ) Incapaz ou tempo $>60$ " - 0 ponto.

67. ASSINALE X NO MOTIVO ABAIXO:

( ) Tentou, mas não conseguiu;

( ) O participante não consegue levantar-se sem auxílio;

( ) O avaliador não teve segurança para realizar o teste;

( ) O participante sentiu-se inseguro para realizar o teste;

( ) O participante não conseguiu entender as instruções do teste;

( )Outro motivo específico:

( ) O participante se recusou.

Comentários:

PONTUAÇÃO FINAL DO SPPB:

Soma Total das pontuações nos 3 Testes:

0 a 3 pontos - incapacidade ou desempenho muito ruim

4 a 6 pontos - baixo desempenho

7 a 9 pontos - moderado desempenho

10 a 12 pontos - bom desempenho

(GURALNIK, 1994) 


\section{ANEXO F Protocolo de Avaliação Clínica Inicial}

Dados de Identificação

Nome:

Data de Nascimento : Sexo:( )M ( )F

Endereço:

Situação Conjugal: ( ) Solteiro ( ) Casado ( ) Separado ( ) Viúvo

Escolaridade em anos:

Profissão:

Ocupação nos últimos cinco anos:

Presença de doença:

( ) Não

( )Sim.Quais

Hábitos:

1. Tabagismo

( ) fumante. Número de cigarros/dia... ( ) ex - fumante ( ) não fumante

3. Medicação

( ) Não

( ) Sim.Quais

4. Moradia

Tipo ( ) casa ( ) apartamento

Há quanto tempo mora em São Paulo? anos

Que cidade morou antes de mudar-se para São Paulo?

Quantas horas permanece em média fora de sua residência por dia? horas

5. Atividade física

( ) Sim. Quais ( ) Não

Frequência ( ) 1x/semana ( ) $2-3 x /$ semana $\quad($ ) $>3 x /$ semana

6. Exame Físico

Peso $(\mathrm{Kg})$ Altura (m) IMC $\left(\mathrm{Kg} / \mathrm{m}^{2}\right)$

Pressão arterial sentada Freqüência cardíaca Sentado 


\section{ANEXO G Avaliação do Desconforto Sonoro}

1. Você notou dificuldade em realizar os testes de memória devido a fatores do ambiente como a presença de ruídos? ( )sim ( )não

2. Você notou dificuldade em realizar os testes de equilíbrio devido a fatores do ambiente como a presença de ruídos? ( )sim ( )não

3. Você notou dificuldade em realizar os testes do aperto de mão devido a fatores do ambiente como a presença de ruídos? ( ) sim （ )não

4. Como você classificaria o desconforto promovido pelo ruído do ambiente?

\begin{tabular}{|c|c|c|c|c|}
\hline $\begin{array}{l}\text { Desconforto } \\
\text { ausente }\end{array}$ & $\begin{array}{l}\text { Mínimo } \\
\text { desconforto }\end{array}$ & $\begin{array}{l}\text { Leve } \\
\text { desconforto }\end{array}$ & $\begin{array}{l}\text { Moderado } \\
\text { desconforto }\end{array}$ & $\begin{array}{l}\text { Intenso } \\
\text { desconforto }\end{array}$ \\
\hline ) & & ( & ( & ( \\
\hline
\end{tabular}

5. Com que frequência você se expõe a ruídos de mesma intensidade no seu dia a dia?

\begin{tabular}{|c|l|l|l|c|}
\hline Nunca & $\begin{array}{l}\text { Menos de } \\
\text { uma vez por } \\
\text { semana }\end{array}$ & $\begin{array}{l}\text { Uma vez por } \\
\text { semana }\end{array}$ & $\begin{array}{l}\text { Mais de uma } \\
\text { vez por } \\
\text { semana }\end{array}$ & Diariamente \\
\hline$(\quad)$ & $(\quad)$ & $(\quad)$ & $(\quad)$ & $(1)$ \\
\hline
\end{tabular}




\section{ANEXO H Bateria de Testes Neuropsicológicos Computadorizado}

\section{TRAIL MAKING A}

Avalia: Atenção e Velocidade

Instruções: Na tela aparecerão alguns números. Comece clicando com o dedo no número 1 (aponte) e a seguir clique com o dedo o número 2 (aponte o 2), depois o 3 (aponte o 3), o 4 (aponte o 4) e assim sucessivamente. Quando você clica adequadamente o número ele muda de cor - de laranja para azul e uma linha aparece ligando os números. Fique atento de que seu toque foi adequado. Na próxima tela você fará a mesma coisa do 1 ao $25 \mathrm{em}$ ordem, até o final. Toque os números na sequência o mais rápido que puder. Pode começar. Avaliador: Indique o início.

\section{Tempo:}

\section{TRAIL MAKING B}

Avalia: Flexibilidade e Velocidade

Instruções: Na tela aparecerão alguns números e letras, misturados. Comece clicando no número 1 (aponte) e siga juntando o número 1 a letra $A$ (aponte $O$ A), a seguir o numero o 2 (aponte $\circ$ 2) a letra B (aponte o B). Sempre alternando uma número e uma letra. Na próxima tela você vai fazer a mesma coisa em ordem crescente dos números e em ordem alfabética das letras, até 0 final. Lembre-se, primeiro você tem um número (aponte o 1), depois uma letra (aponte o A), então um número (aponte o 2) e uma letra (aponte o B), e assim sucessivamente. Quando você clica adequadamente o número ou letra ele muda de cor - de laranja para azul e uma linha aparece ligando os números às letras. Fique atento de que seu toque foi adequado. Faça a sequencia o mais rápido que puder. Pode começar.

Avaliador: Indique o início.

Tempo:

\section{SPACIAL RECOGNITION}

Avalia: Memória Espacial

Instruções: Cinco quadrados iguais irão aparecer na tela, uma de cada vez, tente memorizar o lugar preciso em que eles aparecem. (Deixe que eles 
apareçam). Agora você verá dois quadrados de cada vez. Escolha aquele que coincide com a localização de um dos 5 quadrados vistos anteriormente.

Número de acertos:

GO/NO-GO

Avalia: Velocidade de Processamento

Instruções: Este teste mede quão rápido você consegue tomar uma decisão simples e então reagir ou inibir sua resposta. Aperte a barra de espaço o mais rápido que puder quando você vir essa fruta. Somente quando for essa fruta! Se for outra fruta não aperte.

Número de erros:

Tempo:

\section{MEMORY SPAN}

Avalia: Memória espacial

Instruções: Na tela aparecerão cartões azuis. Eles irão se iluminar de laranja numa dada sequência. Observe a sequência. A seguir você deverá tocar nos cartões na mesma ordem em que eles se iluminaram. Pode ser que um cartão se repita na sequência, se ele aparecer 2 vezes clique nele 2 vezes. Quando você clica adequadamente no cartão ele muda da cor azul para a laranja por um breve período. Fique atento de que seu toque foi adequado. Quando você erra o computador interrompe o teste e imediatamente começa uma nova sequência de mesmo tamanho. Fique atento à nova sequência e esqueça o erro. Neste teste o tempo não conta.

Número de acertos de sequências:

PATTERN RECOGNITION

Avalia: Memória Visual

Instruções: Você verá uma série de 12 formas. Tente memorizar as figuras que aparecem, prestando atenção nos detalhes e na direção das imagens. (As imagens vão aparecer). Agora você verá duas figuras de cada vez. Toque na que você viu anteriormente.

Número de acertos:

REVERSE MEMORY SPAN

Avalia: Memória Operacional

Instruções: Toque nos cartões na ordem inversa em que eles aparecem. 
Instruções: $\mathrm{Na}$ tela aparecerão cartões azuis. Eles irão se iluminar de laranja numa dada sequência. Observe a sequência. A seguir você deverá tocar nos cartões na ordem inversa em que eles se iluminaram. Pode ser que um cartão se repita na sequência, se ele aparecer 2 vezes clique nele 2 vezes também. Quando você clica adequadamente no cartão ele muda da cor azul para a laranja por um breve período. Fique atento de que seu toque foi adequado. Quando você erra o computador interrompe o teste e imediatamente começa uma nova sequência de mesmo tamanho. Neste teste o tempo não conta.

Número de acertos:

\section{DIGIT SPAN}

Avalia: Memória de Curto Prazo

Direto Instruções: Vou falar uma sequência numérica, e cada algarismo será falado individualmente e pausadamente, iniciando com 2 algarismos. Memorize e quando eu acabar, você deve repeti-los na mesa ordem. A cada série correta o número de dígitos vai aumentar em 1 algarismo: 2, 3, 4 etc ... ATENÇÃO: Se aparecer 6, dizer seis e não meia. Tempo para exibição de cada número é de $1 \mathrm{~s}$.

Número de acertos de sequências:

\section{REVERSE DIGIT SPAN}

Avalia: Memória de Trabalho

Instruções: Vou falar uma sequência numérica, e cada algarismo será falado individualmente e pausadamente, iniciando com 2 algarismos. Memorize e quando eu acabar,você deve repeti-los na ordem inversa. A cada série correta o número de dígitos vai aumentar em 1 algarismo: 2, 3, 4 etc ... Por exemplo se eu disser 123 diga 321 ATENÇÃO: Se aparecer 6, dizer seis e não meia. Tempo para exibição de cada número é de $2 \mathrm{~s}$.

Número de acertos de sequências: 
ANEXO I Avaliação da Força Muscular Voluntária

Teste de preensão palmar

Dominância:

Mão direita

1a medida kgf

$2^{\text {a }}$ medida kgf

3몰 medida kgf
Mão esquerda

1르medida kgf

$2^{\text {a }}$ medida__ $\mathrm{kgf}$

3amedida kgf 


\section{REFERÊNCIAS}

Andrade CRF, Schochat E. Perfil audiométrico de trabalhadores de indústrias ruidosas. In: Anais do I Encontro Nacional de Fonoaudiologia Social e Preventiva - Conselho Regional de Fonoaudiologia Região 2; 1988; São Paulo. São Paulo; p. 71-81.

Araujo MT, Caldas RN. Exercício físico na melhor idade: uma prescrição com "novos olhares" para "velhos conceitos". Rev. baiana de Educ. Fís. Salvador. 2002; 41(3):47-57.

Ardilla A, Ostrosky-Solis F, Rosselli M, Gomez C. Age-related cognitive decline during normal aging: the complex effect of education. Arch Clin Neuropsychol. 2007;15(6):495-513.

Argimon IIL, Stein LM. Habilidades cognitivas em indivíduos muito idosos: um estudo longitudinal. Rev Saúde Pub.2005;21:64-72.

Baraldi GS, Almeida LC, Borges ACC. Evolução da perda auditiva no decorrer do envelhecimento. Braz J Otorhinolaryngol. 2007;73(1):64-70.

Bates ME, Voelbel GT, Buckman JF, Labouvie EW, Barry D.Short-term neuropsychological recovery in clients with substance use disorders. Alcoholism: Clinical and Experimental Research. 2005; 29:367-77.

Beglinger LJ, Gaydos B, Kareken DA, Tangphao-Daniels O, Siemers E, Mohs R. Neuropsychological test performance in healthy volunteers before and after Donepezil administration. Journal of Psychopharmacology. 2004;18:102-8.

Belojevic G, Jakovlevic, B. Subjective Reactions for Traffic Noise with Regard to some Personality Traits. Environmental International.1997; 23: 221-226. 
Belojevic G, Slepcevic V, Jakovljevic B. Mental performance in noise: The role of introversion. J Environ Psychol .2001;21:209-13.

Berardi A, Parasuraman R, Haxby J. Overall vigilance and sustained attention decrements in health aging. Exp. Aging Res. 2001; 27(1):19-39.

Bertolucci PHF, Brucki SMD, Campacci SR, Juliano Y. O mini-exame do estado mental em uma população geral: impacto da escolaridade. Arq. Neuropsiquiatr.1994; 52:1-7.

Bizzo G, Guillet, N, Patat A, Gagey PM. Specifications for building a vertical force plataform designed for stabilometry. Med Bio Eng Comput. 1985; 23(5):474-6.

Brito F. A transição demográfica no Brasil: as possibilidades e os desafios para a economia e a sociedade. Minas Gerais: Cedeplar; 2007. p.308.

Broadbent DE. The current state of noise research: Reply to Poulton. Psychological Bulletin. 1978; 85:1052-1067.

Cabeza R, Anderson ND, Locantore JK, Mclntosh AR Aging gracefully: compensatory brain activity in high-performing older adults. Neuroimage. 2002; 17(3):1394-402.

Calais LL, Borges ACLC, Baraldi GS, Almeida LC. Queixas e preocupações otológicas e as dificuldades de comunicação de indivíduos idosos. Rev Soc Bras Fonoaudiol. 2008;13(1):12-9.

Camarano AA, Pasinato MT. Introdução. In: Camarano AA. (editor). Os Novos Idosos Brasileiros: muito além dos 60? Rio de Janeiro: IPEA; 2004.

Cançado FAX, Horta ML. Envelhecimento cerebral. In: Freitas EV, et al. Tratado de Geriatria e Gerontologia. Rio de Janeiro: Guanabara Koogan; 2002. p.112127. 
Cassidy G, MacDonald RAR. The effect of background music and background noise on the task performance of introverts and extraverts. Psychology of Music. 2007; 35: 517-37.

Chandler JM. Equilíbrio e quedas no idoso: questões sobre a avaliação e o tratamento. In: Guccione AA. Fisioterapia Geriátrica. Rio de Janeiro: Guanabara Koogan. 2002. p.265-77.

Comfort A. The myth of senility. Diagnosing nonspecific major illness in the elderly. Postgrad Med.1979;65:130-42.

Cordeiro R, Lima-Filho EC, Nascimento LCR. Associação da perda auditiva induzida pelo ruído com o tempo acumulado de trabalho entre motoristas e cobradores. Cad Saúde Pública. 1994; 10:210-21.

Costa CB, Gama WU, Momensohn-Santos TM. Eficácia do protetor auditivo de inserção em programa de prevenção de perdas auditivas. Arq. Int. Otorrinolaringol. 2009; 13(3): 281-6.

Colleoni, N.; Cols, L. Ruídos industriais, perturbações auditivas e sua profilaxia. Revista brasileira de saúde ocupacional.1981; 36; 77-80.

Craik FIM. Changes in memory with normal aging: a functional view. In: Wurtman RJ, Corkin S, Growdon JH, Ritter-Walker E. Advances in Neurology Vol. 51, Alzheimer's Disease. New York: Raven Press, 1990.p.201-205.

Cutler SJ, Hendricks J, Guyer A. Age Differences in Home Computer Availability and Use. Journal of Gerontology: Social Sciences. 2003;5(58B): S271-80.

Dani A; Garavelli, SL. Principais impactos da Poluição Sonora dos Seres Humanos. Rev. Universa. Brasil. 2001;9(4);659-78. 
Dixon RA, Hertzog C, Friesen IC, Hultsch DE. Assessment of intraindividual change in text recall of elderly adults. In: Brownell $\mathrm{HH}$, Joanette $\mathrm{Y}$. Narrative discourse in neurologically impaired and normal aging adults. San Diego: Singular Publ Group; 1993. p.77-101.

Duarte YAO, Diogo MJD. Atendimento domiciliar: um enfoque gerontológico. São Paulo: Atheneu, 2000.

Duff K, Callister C, Dennett K, Tometich D .Practice Effects: A Unique Cognitive Variable. The Clinical Neuropsychologist. 2012; 26(7): 1117-27.

Faisal AA, Selen LP, Wolpert DM. Noise in the nervous system, Nat Rev Neurosci.2008; 9(4): 292-303.

Ferrucci L, Guralnik JM, Studenski S, Fried LP, Cutler GB Jr, Walston JD. Designing randomized, controlled trials aimed at preventing or delaying functional decline and disability in frail, older persons: a consensus report. J Am Geri.2004;52:625-34.

Fidel, IS. Nationwide urban noise survey. Journal of the Acoustical Society of America 1978; 64: 198-106.

Figueiredo K, Lima K, Guerra R. Instrumentos de avaliação do equilíbrio corporal em idosos. Revista Brasileira de Cineantropometria \& Desempenho Humano. 2007;9(4):408-13.

Folstein MF, Folstein SE, McHugh PR. Mini-mental state: a practical method for grading the cognitive state of patients for the clinician. J Psychiatric Res. 1975;12:189-98.

Fournet N; Roulin JL; Vallet F; Beaudoin M; Agrigoroaei S; Paignon A; Dantzer $\mathrm{C}$; Desrichard O.Evaluating short-term and working memory in older adults: French normative data.Aging Ment Health. 2012; 16(7): 922-30. 
Freitas, APM. Estudo o impacto ambiental causado pelo aumento da poluição sonora em áreas próximas aos centros de lazer noturno na cidade de Santa Maria - RS. [dissertação]. Santa Maria: Faculdade de Engenharia civil, Universidade Federal de Santa Maria, 2006.

Gananca MM, Caovilla HH, Munhoz MSL, Silva MLG, Gananca FF, Gananca CF. A Hodologia Clinica do Sistema Vestibular. Em: Caovilla HH, Gananca MM, Munhoz MSL, Silva MLG. Equilibriometria Clinica. São Paulo: Atheneu; 2000. p. $5-21$.

Geoffroy MC, Hertzman C, Li L, Power C. Morning salivary cortisol and cognitive function in midlife: evidence from a population-based birth cohort. Psychological Medicine. 2012;42:1763-73.

Gerges SNY. Noise in large cities in Brazil. Journal of the Acoustical Society of America, 147th Meeting of the Acoustical Society of America. 2004; 115(5): 2592.

Gompertz P, Pound P, Ebrahim S. Validity of the extended activities of daily living scale. Clin Rehab. 1994; 8: 275-80.

Gonçalves DFF, Ricci NA, Coimbra AMV..Equilíbrio funcional de idosos da comunidade; comparação em relação ao histórico de quedas. Revista Brasileira de Fisioterapia. 2009;13(4):316-23.

Green RC, Green J, Harrison JM. Screening for cognitive impairment in older individuals. Arch Neurolol.1994;51, 779-786.

Griffiths, I.D.; Langdon, F.J. Subjetive response to road traffic noise. Journal of Sound and Vibration 1986; 8: 16-32.

Gullian E. Effects of noise on reaction time and induced muscle tension. Rev Roum Sci Soc Ser Psychol. 1967;13:371-85. 
Guralnik JM, Simonsick EM, Ferrucci L, Glynm RJ, Berkman LF, Blazer DG, et al. A short physical performance battery assessing lower extremity function: association with self-reported disability and prediction of mortality and nursing home admission. J Gerontol.1994;49(2):85-94.

Henderson D, Subramania M, Boettcher FA. Individual susceptibility to noise indeed hearing loss: an old topic revisited. Ear Hear. 1993;14(3):152-68.

Horak FB, Macpherson JM. Postural orientation and equilibrium, In: Rowell LB., Sherpherd JT. (Ed.) Handbook of physiology: a critical, comprehensive presentation of physiological knowledge and concepts. New York: Oxford American Physiological Society,1996. p.255-92.

Horg OS, Raymond DM. How serious is hearing loss among US construction workers? In: Anais do XXVII International Congress on Occupational Health [CDROM]. Foz do Iguaçu: International Commission on Occupational Health; 2003.

Hsu KE, Man FY, Gizicki RA, Feldman LS, Fried GM. Experienced surgeons can do more than one thing at a time: effect of distraction on performance of a simple laparoscopic and cognitive task by experienced and novice surgeons. Surg Endosc. 2008; 22:196-201.

Instituto Brasileiro de Geografia e Estatística. Pesquisa Nacional de Amostra de Domicílio 2012. Brasília, 2012a. [citado 14 dez. 2013]. Disponível em: ftp://ftp.ibge.gov.br/Trabalho_e_Rendimento/Pesquisa_Nacional_por_Amostra_d e_Domicilios_anual/2012/tabelas_pdf/sintese_ind_1_1.pdf.

Instituto Brasileiro de Geografia e Estatística. Tábuas Completas de Mortalidade 2012. Brasília, 2012b. [citado 14 dez. 2013]. Disponível em: http://www.ibge. gov.br/home/estatistica/populacao/tabuadevida/2012/default.shtm 
Instituto Brasileiro de Geografia e Estatística. Censo demográfico 2010. Brasília: 2011. [citado 14 dez. 2013] Disponível em: http://www.ibge.gov.br/home/ estatistica/ população/censo2010/default_sinopse.shtm

Jacob Filho W, Santarém JM, Flô C, Mônaco T. Conceitos e definições. In: Jacob Filho W, Santarém JM, Flô C, Mônaco T, editores. Atividade física e envelhecimento saudável. 1a Ed. São Paulo: Atheneu;2005. p 1-7.

Job RFS. Noise sensitivity as a factor influencing human reactions to noise. Noise \& Health. 1999; 3, 57-68.

Juola JF, Koshino H, Warner CB, McMickell M, Peterson M. Automatic and voluntary control of attention in young and older adults. $A m \mathrm{~J}$ Psychol. 2000;113(2):159-78.

Kalache A. O mundo envelhece: é imperativo criar um pacto de solidariedade social. Ciênc.Saúde Coletiva. 2008; 13(4):1017- 111.

Katz S, Ford AB, Moskowitz RW, Jackson BA, Jaffe MW. Studies of illness in the aged. The index of ADL: a standardized measure of biological and psychological function. JAMA.1963; 185: 914-9.

Katzman R, Aronson M, Fuld P, Kawas C, Brown T, Morgenstern $\mathrm{H}$, et al., Development of dementing illnesses in an 80-year old volunteer cohort. Ann Neurol. 1989; 25(4):317-24.

Kemppainen NM, Aalto S, Karrasch M, Någren K, Savisto N, Oikonen V,et al. Cognitive reserve hypothesis: Pittsburgh Compound B and fluorodeoxyglucose positron emission tomography in relation to education in mild Alzheimer's disease. Ann Neurol. 2008 Jan; 63(1):112-8.

Kjellberg A, Sköldströ MB. Noise annoyance during the performance of different non-auditory tasks. Perceptual and Motor Skills. 1991; 73:39-49. 
Klidjian AM, Foster KJ, Kammerling RM, Cooper A, Karran SJ. Relation of anthropometric and dynamometric variables to serious postoperative complications. BJM. 1980; $281: 899-901$.

Koelega HS, Brinkman JA, Bergman $H$. No effect of noise on vigilance performance? Human Factors. 1986;28:581-93.

Laitinen $\mathrm{H}$. Factors affecting the use of hearing protectors among classical music players. Noise Health. 2005; 7(26): 21-9.

Lawton MP, Brody EM. Assessment of older people: self maintaining and instrumental activities of daily living. Gerontologist.1969; 9: 179-86.

Lezak MD, Howieson D, Bigler E, Tranel D. Neuropsychological assessment (5th ed.). New York: Oxford University Press; 2012.

Lipp, MEN. O modelo quadrifásico do stress. In: Lipp MEN, editor. Mecanismos neuropsicofisiológicos do stress: Teoria e aplicações clínicas.São Paulo: Casa do Psicólogo; 2003. p. 17-21.

Lord SR. Ward JA, Williams P, Anstey K. Physiological factors associated with falls in older community-dwelling women. J Am Geriatric Soc. 1994;42:1110-17.

Magalhães FH, Kohn AF. Vibration-enhanced posture stabilization achieved by tactile supplementation: May blind individuals get extra benefits? Medical Hypotheses. 2011;77:301-304.

$\mathrm{Ma} \mathrm{H}$, Yano,T. An experiment on auditory and non-auditory disturbances caused by railway and road traffic noises in outdoor conditions. Journal of Sound and Vibration. 2004; 277:501-9.

Mainenti MRM, Oliveira LF, Lima MAMT, Nadal J. Stabilometric sinal analysis in tests with sound stimuli. Exp. Brain. Res. 2007; 181:229-236. 
Marchant DC; Greig M; Scott C. Attentional focusing instructions influence force production and muscular activity during isokinetic elbow flexions. J Strength Cond Res; 23(8): 2358-66, 2009.

Maschek, C. Preventive Medical Limits for Chronic Traffic Noise Exposure. Acustica 1999; 85: 448.

Mayr U, Kliegl R. Task-set switching and log-term memory retrieval. Journal Exp. Psychol. Learn Mem. Cong. 2000;26(5):1124-40.

Melnick W. Evaluation of industrial hearing conversation programs: a rewiew and analysis. Am. Ind. Hyg. Ass. Journal. 1984; 45(7): 459-67.

Melzer I, Damry E, Landau A, Yagev R. The influence of an auditory-memory attention-demanding task on postural control in blind persons. Clinical Biomechanics. 2011;26(4):358-362.

Memória, CM. Propriedades psicométricas de CANS-MCI: um teste computadorizado para avaliação do comprometimento cognitivo leve em idosos [dissertação]. São Paulo: Faculdade de Medicina. Universidade de São Paulo: 2012.

Mendes MM, Morata, TC, Marques JM. Aceitação dos protetores auditivos pelos componentes de banda instrumental e vocal. Rev. Bras. Otorrinolaringol. 2007; 73(6): 785-92.

Miedema HME, Vos $\mathrm{H}$. Noise sensitivity and reactions to noise and other environmental conditions. Journal of the Acoustical Society of America. 2003;113, 1492- 504 .

Milonski J, Olsewski J. The evaluaton of usefullness of hearing protectors while exposure to impulse noise. Otolaryngol Pol. 2007;61 (5): 877-9. 
Monat A, Lazarus RS, Reevy G. Praeger Handbook of stress and coping. Churchill Livingstone: Greenwood; 2007.

Morasso PG, Schieppati M. Can muscle stiffness alone stabilize upright standing?.Journal of Physiology. 1999;82:1622-26.

Munhoz MSL, Silva MLG, Caovilla HH, Gananca MM, Frazza MM. Neuroanatomofisiologia da Audição. In: Munhoz MSL, Caovilla HH,Silva MLG, Gananca MM. Audiologia Clinica. São Paulo: Atheneu; 2003. p. 19-43.

NeuroCom Internnational Inc. Balance Master Operator's Manual. Clackamas, Oregon: 2002.

O’Brien JT, Schweitzer I, Ames D, Tuckwell V, Mastwyk M. Cortisol suppres-sion by dexamethasone in the healthy elderly: effects of age, dexamethasonelevels, and cognitive function. Biological Psychiatry. 1994;36:389-94.

Paixão JR. MC, Heckamnn M. Distúrbios da postura, marcha e quedas. In: Freitas EV, et.al.. Tratado de geriatria e gerontologia. Rio de Janeiro: Guanabara Koogan;2002.p.624-34.

Paixão JR, MC, Heckamnn M. Uma revisão sobre instrumentos de avaliação do estado funcional do idoso. Cad. Saúde Pública. 2005; 21(1):7-19.

Patla J, Frank D. Winter Assessment of balance control in the elderly: major issues. Physiother Can.1990;42:89-97.

Petian A. Incômodo em relação ao ruído urbano entre trabalhadores de estabelecimentos comerciais no município de São Paulo [tese]. São Paulo: Faculdade de Medicina, Universidade de São Paulo; 2008.

Pimentel-Souza F. A Poluição Sonora ataca traiçoeiramente o corpo. In: Associação Mineira de Defesa do Meio Ambiente (AMDA), Apostila: Meio 
Ambiente em Diversos Enfoques, "Projeto Jambreiro". Belo Horizonte; 1992. p. 24-6.

Poulton EC. Composite model for human performance in continuous noise. Psychological Review. 1979; 86, 361-375.

Priplata AA, Niemi JB, Harry JD, Lipsitz LA, Collins JJ. Vibrating insoles and balance control in elderly people. Lancet. 2003;362(9390):1123-4.

Ramos LR. Fatores determinantes do envelhecimento saudável em idosos residentes em centro urbano: Projeto Epidoso. Caderno de Saúde Pública, 2003;19(3):793-97.

Rapport LJ, Brines DB, Axelrod BN, Theisen ME. Full scale IQ as mediator of practice effects: The rich get richer. The Clinical Neuropsychologist. 1997;11:375-80.

Raymond PD, Hinton-Bayre AD, Radel M, Ray MJ, Marsh NA. Test-retest norms and reliable change indices for the Microcog battery in a healthy community population over 50 years of age. Clin Neuropsychol. 2006;20:261-70.

Ronnlund M, Nilsson L. Adult life-span patterns in WAIS-R block design performance: cross-sectional versus longitudinal age gradients and relations to demographic factors. Intelligence. 2006;34(1):63-78.

Rosa, TEC, Benício, MHA, Latorre, MRDO, Ramos, LR. Fatores determinantes da capacidade funcional entre idosos. Revista de Saúde Pública. 2003;37(1): 408.

Russo ICP. Acústica e psicoacústica aplicadas à fonoaudiologia. São Paulo: Lovise Científica;1999. 
Ruwer SL, Rossi AC. Simon L.F Balance in elderly. Rev. Bras. Otorrinolaringgol.2005;71: 298-303.

Salthouse TA. Effects of age on time-dependent cognitive change. Psychological Science.2011;22:682-8.

Salthouse TA, Schroeder DH, Ferrer E. Estimating retest effects in longitudinal assessments of cognitive functioning in adults between 18 and 60 years of age. Developmental Psychology. 2004;40:813-22.

Salthouse TA, Toth J, Daniels K, Parks C, Pak R, Wolbrette M, et al. Effects of Aging on Efficiency of Task Switching in a Variant of the Trail Making Test. Neuropsychology.2000;1(1):102-11.

Schubert MC, Minor LB. Vestibulo-ocular physiology underlying vestibular hypofunction. Physical Therapy. 2004;84(4): 373-85.

Seligman J. Sintomas e Sinais da PAIR: In. Nudelmann AA., Costa EA, Selligman J, Ibanez RN, editores. PAIR: Perda Auditiva Induzida pelo Ruído. Porto Alegre: Bagaggem Comunicação; 1997. p.143-151.

Selye $\mathrm{H}$. The general adaptation syndrome and the diseases of adaptation. J. Clin. Endocrin. Metab.1946; 6:117-96.

Sheikh JI, Yesavage JA. Geriatric Depression Scale (GDS): Recent evidence and development of a shorter version. Clinical Gerontology: A Guide to Assessment and Intervention. NY: The Haworth Press; 1986. p.165-173.

Shumway-Cook A, Woollacott M. Motor Control: Theory and Pratical Applications. Baltimore:Lippincott Williams and Wilkins; 1995.

Silva IFO. Aspectos do envelhecimento cerebral e função cognitiva em modelo experimental animal e estudo de mecanismos de neurodegeneração em cultura 
celular [tese]. Belo Horizonte: Faculdade de Medicina, Universidade Federal de Minas Gerais; 2007.

Sirvinskas, LP. Manual de direito ambiental. 3 ed. São Paulo: Saraiva, 2005, p. 185.

Siu K, Suh IH, Mukherjee M, Oleynikov D, Hide NS. The impact of environmental noise on robot-assisted laparoscopic surgical performance. Surgery, 2010;147(1):107-113.

Steffener J, Reuben A, Rakitin BC, Stern Y. Supporting performance in the face of age-related neural changes: testing mechanistic roles of cognitive reserve. Brain Imaging and Behavior.2011; 5:212-21.

Stern Y. What is cognitive reserve? Theory and research application of the reserve concept. Journal of the International Neuropsychological Society. 2002; 8(3): 448-60.

Stern Y, Zarahn E, Habeck C, Holtzer R, Rakitin BC, Kumar A et al. A common neural network for cognitive reserve in verbal and object working memory in young but not old. Cerebral Cortex. 2008; 18(4):959-967.

Sternberg DA, Ballard K, Hardy JL, Katz B, Doraiswamy PM, Scanlon M. The largest human cognitive performance dataset reveals insights into the effects of lifestyle factors and aging. Frontiers in Human Neurocience. 2013; (7)292:1-10.

Stoffregen TA., Pagukayan RJ, Bardy BG, Hettinger LJ. Modulatingpostural control to facilitate visual performance. Human Movement Science. 2000;19: 203-20.

Sørensen M, Andersen MHZJ, Nordsborg RB; Lillelund KG; Jakobsen J; Tjønneland A, et al. Road traffic noise and stroke: a prospective cohort study Eur Heart J . 2011; 32(6):737-44. 
Sousa MGC, Russo ICP. Audição e percepção da perda auditiva em idosos. Rev Soc Bras Fonoaudiol. 2009; 14(2):241-6.

Suter AH. Construction noise: exposure, effects, and the potential for remediation; A review and analysis. AlHA Journal. 2002; 63: 768-89.

Szalma JL, Hancock AP. Noise Effects on Human Performance: A Meta-Analytic Synthesis. Psychological Bulletin American Psychological Association. 2011;137(4): 682-707.

Tafalla R, Evans GW, Cohen A. Noise and human performance: the potential role of effort. In: Berglund B, Bergland U, Karlsson J, Lindvall T. Proceedings of the fitth international congress on noise as a public health problem. Stockholm: Swedish Council for Building Research, 1988;(3): 95-100.

Teixeira CS, Korbes DR, Garcia A. Ruído e equilíbrio: aplicação da posturografia dinâmica em indústria gráfica. Rev.CEFAC. 2011;13(1):92-1001.

Temkin NR, Heaton RK, Grant I, Dikmen SS. Detecting significant change in neuropsychological test performance: A comparison of four models. Journal of the International Neuropsychological Society. 1999; 5:357-69.

Thompson C, Bélanger M , Fung J. Effects of plantar cutaneo-muscular and tendon vibration on posture and balance during quiet and perturbed stance. Human Movement Science. 2011;30(2):153-71.

Ulatowska HK, Cannito MP, Hayashi MM, Fleming SG. Language abilities in the elderly. In: Ulatowska HK. The aging brain: communication in the elderly. London: Taylor \& Francis; 1985.p.125-39.

United Nations. World population prospects - the 2008 revision. New York: Department of Social and Economic Affairs - Population Division, 2009. 
Van Hooren S, Valentijn A, Bosma H, Ponds RW, Van Boxtel MP, Jolles J. Cognitive functioning in health older adults aged 64-81: a cohort study into the effects of age, sex and education. Neuropsychol Dev Cogn B Aging Neuropsychol Cogn. 2007;14(1):40-54.

Van Praag H, Christie BR, Sejnowski TJ, Gage FH. Running enhances neurogenesis, learning, and long-term potentiation in mice. Proc Natl Acad Sci. 1999; 96(23):13427-31.

Veras R. Envelhecimento populacional contemporâneo: demandas, desafios e inovações. Rev. Saúde Pública. 2009;43( 3 ):548-54.

Verhaeghen, P; Cerella J. Aging executive control and attention: a rewiew of meta-analyses. Neurosci Biobehav Rev. 2002;26(7): 849-57.

Zannin PHT, Diniz FB, Calixto A, Barbosa, WA. Environmental noise pollution in residential areas of the city of Curitiba. Acta Acustica. 2001;87:625-62.

Zannin PHT, Diniz FB, Calixto A, Ferreira JA, Schulli RB. Incômodo causado pelo ruído urbano à população de Curitiba, PR. Rev. Saúde Pública. 2002; 36 (4): $521-4$.

Zannin PHT, Diniz FB, Calixto A, Ferreira JA. A Survey of Urban Noise Annoyance in a Large Brazilian City: The Importance of a Subjective Analysis in conjunction with an Objective Analysis, 2003. Environmental Impact Assessment Review. 2003; 23: 245-55.

Zimmer K, Ellermeier W. Psychometric properties of four measures of noise sensitivity: a comparison. Journal of Environmental Psychology.1999; 19:95-302.

World Health Organization (WHO). Résumé D'orientation Des Directives De l'oms Relatives Au Bruit Dans l'environmental [internet]. 2003 [cited 2011 abril 25] Available from: http://www.who.int/homepage/primers. 
World Health Organization. New evidence from WHO on health effects of traffic related noise in Europe. Bonn and Copenhagen, 30 March 2011. [cited 14 dez. 2013] Available from: http://www.euro.who.int/en/media-centre/sections/latestpress-releases/new-evidence-from-who-on-health-effects-of-traffic-related-noisein-europe.

World Bank. Population aging: is Latin America ready? Directions in development. Washington DC: World Bank; 2011.

Wu F, Wang R, Jin D, Hu X, Yang Y, Zhang J, et al. Effect of Noise-Enhanced on the Balance Control Ability in Older Adults. In: Duffy VG. (ed.). Digital Human Modeling. Heidelberg:Berlin. Springer-Verlag. 2007. p. 483-489, 2007. 


\section{Apêndice}

Valores Normais de LoS

Reaction Time (RT) (sec)

Back

Right

Left

Composite

Forward

$\begin{array}{lllllllllll}\text { Age } & \text { Mean } & \text { SD } & \text { Mean } & \text { SD } & \text { Mean } & \text { SD } & \text { Mean } & \text { SD } & \text { Mean } & \text { SD } \\ 20-39 & 0.62 & 0.20 & 0.45 & 0.17 & 0.68 & 0.23 & 0.70 & 0.25 & 0.61 & 0.17 \\ 40-59 & 0.73 & 0.25 & 0.55 & 0.20 & 0.70 & 0.22 & 0.76 & 0.25 & 0.68 & 0.17 \\ 60-69 & 0.91 & 0.39 & 0.64 & 0.39 & 0.96 & 0.37 & 1.09 & 0.60 & 0.90 & 0.36 \\ 70-79 & 1.02 & 0.38 & 0.74 & 0.37 & 1.20 & 0.52 & 1.20 & 0.74 & 1.05 & 0.37\end{array}$

Movement Velocity (MVL) (deg/sec)

\begin{tabular}{lllllllllll} 
Forward & \multicolumn{3}{c}{ Back } & \multicolumn{4}{c}{ Right } & \multicolumn{2}{c}{ Left } & \multicolumn{3}{c}{ Composite } \\
Age & Mean & SD & Mean & SD & Mean & SD & Mean & SD & Mean & SD \\
$20-39$ & 6.6 & 2.1 & 2.7 & 1.1 & 6.7 & 2.7 & 7.3 & 2.8 & 5.8 & 1.8 \\
$40-59$ & 5.2 & 1.8 & 3.0 & 1.2 & 5.7 & 2.1 & 6.2 & 2.6 & 5.0 & 1.5 \\
$60-69$ & 4.3 & 1.2 & 2.1 & 0.9 & 4.9 & 1.8 & 4.7 & 1.5 & 4.0 & 1.1 \\
$70-79$ & 3.4 & 1.7 & 2.2 & 0.9 & 4.3 & 2.5 & 4.3 & 1.9 & 3.5 & 1.6
\end{tabular}

End Point Excursion (EPE) (\% of LOS)

\begin{tabular}{|c|c|c|c|c|c|c|c|c|c|c|}
\hline \multicolumn{2}{|l|}{ Forward } & \multicolumn{2}{|l|}{ Back } & \multicolumn{2}{|l|}{ Right } & \multicolumn{2}{|c|}{ Left } & \multicolumn{3}{|c|}{ Composite } \\
\hline Age & Mean & $S D$ & Mean & $S D$ & Mean & $S D$ & Mean & $S D$ & Mean & $S D$ \\
\hline $20-39$ & 99.8 & 12.9 & 47.0 & 18.5 & 93.6 & 11.6 & 100.9 & 15.1 & 85.3 & 10.1 \\
\hline $40-59$ & 89.7 & 14.9 & 58.0 & 16.2 & 90.1 & 15.9 & 101.4 & 13.9 & 84.9 & 8.3 \\
\hline $60-69$ & 79.2 & 18.2 & 44.2 & 18.5 & 82.2 & 16.8 & 81.8 & 14.8 & 72.0 & 9.1 \\
\hline $70-79$ & 71.0 & 19.2 & 49.7 & 17.2 & 80.8 & 15.9 & 79.6 & 22.7 & 69.0 & 14.5 \\
\hline \multicolumn{11}{|c|}{ Maximum Excursion (MXE) (\% LOS) } \\
\hline \multicolumn{2}{|c|}{ Forward } & \multicolumn{2}{|c|}{ Back } & \multicolumn{2}{|c|}{ Right } & \multicolumn{2}{|c|}{ Left } & \multicolumn{3}{|c|}{ Composite } \\
\hline Age & Mean & $S D$ & Mean & $S D$ & Mean & $S D$ & Mean & $S D$ & Mean & $S D$ \\
\hline $20-39$ & 106.3 & 9.4 & 58.9 & 19.3 & 107.7 & 8.2 & 111.5 & 10.2 & 96.2 & 6.7 \\
\hline $40-59$ & 101.0 & 11.9 & 73.1 & 16.5 & 105.9 & 10.7 & 111.5 & 10.2 & 98.0 & 5.9 \\
\hline $60-69$ & 93.6 & 18.0 & 58.6 & 20.7 & 98.1 & 15.3 & 99.3 & 13.5 & 87.6 & 9.6 \\
\hline $70-79$ & 90.0 & 26.8 & 67.6 & 21.9 & 97.5 & 15.2 & 97.7 & 24.5 & 86.8 & 17.4 \\
\hline \multicolumn{11}{|c|}{ Directional Control (DCL) (\% straight line path) } \\
\hline \multicolumn{2}{|l|}{ Forward } & \multicolumn{2}{|c|}{ Back } & \multicolumn{2}{|l|}{ Right } & \multicolumn{2}{|c|}{ Left } & \multicolumn{3}{|c|}{ Composite } \\
\hline Age & Mean & $S D$ & Mean & $S D$ & Mean & $S D$ & Mean & $S D$ & Mean & $S D$ \\
\hline 20-39 & 84.6 & 7.7 & 45.9 & 17.0 & 78.5 & 8.7 & 80.9 & 8.7 & 72.6 & 7.6 \\
\hline $40-59$ & 83.2 & 10.1 & 53.3 & 13.7 & 79.3 & 9.9 & 84.7 & 7.8 & 75.2 & 6.0 \\
\hline $60-69$ & 80.8 & 13.3 & 46.5 & 18.6 & 74.1 & 12.1 & 79.2 & 8.2 & 70.7 & 7.9 \\
\hline $70-79$ & 73.7 & 14.0 & 57.2 & 19.9 & 78. & & .1 & 79.7 & 14.3 & 73.5 \\
\hline
\end{tabular}

NeuroCom Internnational Inc. Balance Master Operator's Manual. Clackamas, Oregon: 2002. 